\title{
UV-Curable Biobased Polyacrylates Based on a Multifunctional Monomer Derived from Furfural
}

\author{
Jules Stouten, Danny E. P. Vanpoucke, Guy Van Assche, and Katrien V. Bernaerts*
}

Cite This: Macromolecules 2020, 53, 1388-1404

Read Online
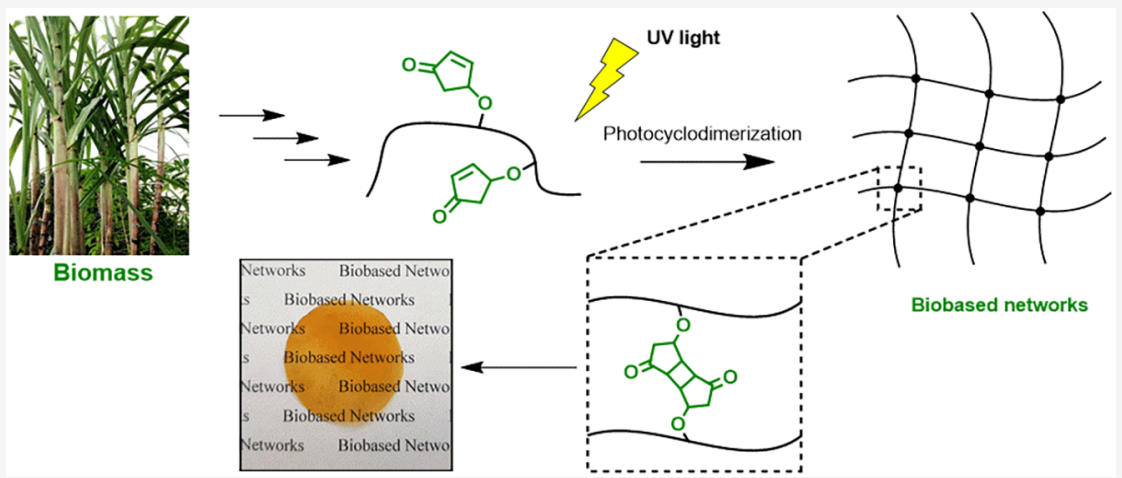

ABSTRACT: The controlled polymerization of a new biobased monomer, 4-oxocyclopent-2-en-1-yl acrylate (4CPA), was established via reversible addition-fragmentation chain transfer (RAFT) (co)polymerization to yield polymers bearing pendent cyclopentenone units. 4CPA contains two reactive functionalities, namely, a vinyl group and an internal double bond, and is an unsymmetrical monomer. Therefore, competition between the internal double bond and the vinyl group eventually leads to gel formation. With RAFT polymerization, when aiming for a degree of polymerization (DP) of 100, maximum 4CPA conversions of the vinyl group between 19.0 and $45.2 \%$ were obtained without gel formation or extensive broadening of the dispersity. When the same conditions were applied in the copolymerization of 4CPA with lauryl acrylate (LA), methyl acrylate (MA), and isobornyl acrylate, 4CPA conversions of the vinyl group between 63 and 95\% were reached. The additional functionality of 4CPA in copolymers was demonstrated by model studies with 4-oxocyclopent-2-en-1-yl acetate (1), which readily dimerized under UV light via $[2+2]$ photocyclodimerization. First-principles quantum mechanical simulations supported the experimental observations made in NMR. Based on the calculated energetics and chemical shifts, a mixture of head-to-head and head-to-tail dimers of (1) were identified. Using the dimerization mechanism, solvent-cast LA and MA copolymers containing 30 mol \% 4CPA were cross-linked under UV light to obtain thin films. The cross-linked films were characterized by dynamic scanning calorimetry, dynamic mechanical analysis, IR, and swelling experiments. This is the first case where 4CPA is described as a monomer for functional biobased polymers that can undergo additional UV curing via photodimerization.

\section{INTRODUCTION}

The conversion of plant-derived chemicals into useful materials has recently become more prominent due to the trend toward sustainability and renewability. In this context, extensive research has been devoted to new and renewable chemicals derived from biomass. The conversion of $\mathrm{C} 5$ and $\mathrm{C} 6$ sugars into platform molecules serves as a major route toward fine chemicals, fuels, and polymers. ${ }^{1,2}$ One of those platform molecules is furfural, which can be converted into furfuryl alcohol. ${ }^{3}$ Although direct conversion into furanoic monomers for aromatic polymers has been subject to extensive investigation, ${ }^{4}$ further conversion of furfuryl alcohol into 4hydroxycyclopentenone $(4 \mathrm{HCP})$ via the Piancatelli rearrangement is also possible (Scheme 1$).^{5}$

4HCP is a versatile molecule with a high functional group density, which allows extensive chemical modification. It has been subjected to a variety of different chemistries including [ $2+$ 2] photocycloaddition, ${ }^{6-12}$ Diels-Alder, ${ }^{13-15}$ 1,4-addition, ${ }^{16-21}[3+2]$ cycloaddition, ${ }^{22,23}$ and the synthesis of esters from the alcohol group of $4 \mathrm{HCP} .^{24} \mathrm{It}$ is recognized as a platform for complex natural products, which mainly include prostaglandins. ${ }^{8}$ Nonetheless, it has never been regarded as a potential monomer in functional polymers until now.

The secondary alcohol of 4HCP allows for acrylation with acryloyl chloride, yielding 4-oxocylopent-2-en-1-yl acrylate (4CPA). Upon polymerization of the acrylate, the pendent

Received: December 16, 2019

Revised: January 23, 2020

Published: February 7, 2020 
Scheme 1. Procedure for the Synthesis of 4-Oxocyclopent-2-en-1-yl Acrylate (4CPA) and Subsequent Reversible AdditionFragmentation Chain Transfer (RAFT) Copolymerization and Photo-Cross-Linking ${ }^{a}$

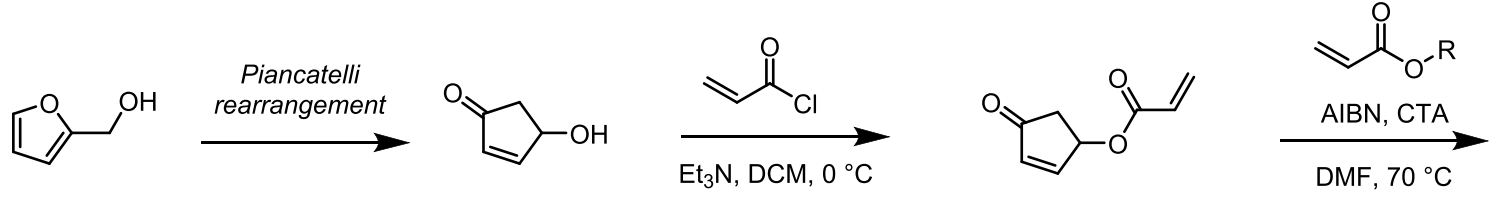

Furfuryl alcohol

(FA)
4-Hydroxycyclopentenone (4HCP) 4-oxocyclopent-2-en-1-yl acrylate

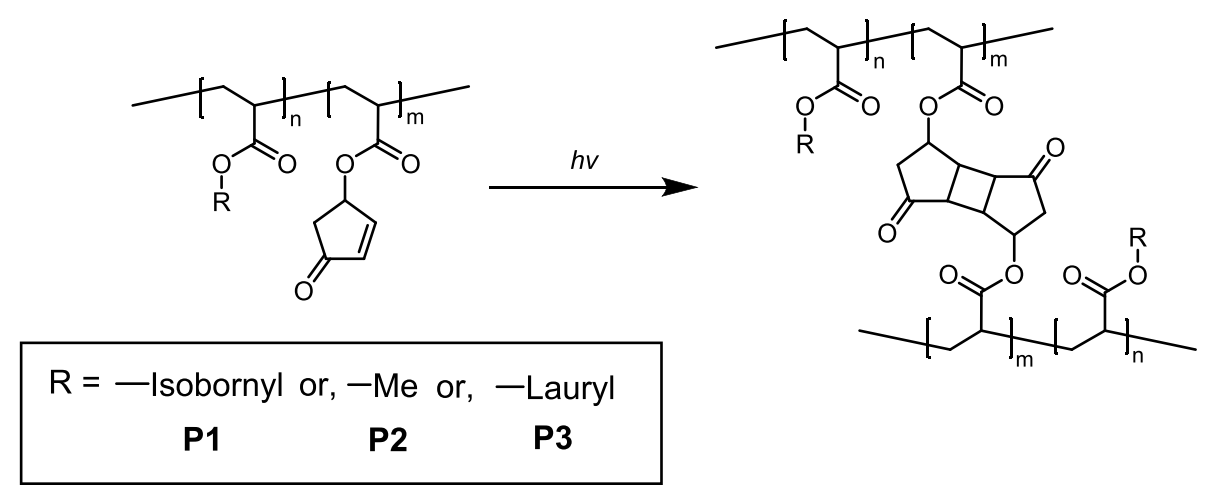

${ }^{a} \mathrm{CTA}=$ chain transfer agent, $\mathrm{R}=-\mathrm{CH}_{3}$ for methyl acrylate, $\mathrm{R}=$ isobornyl for isobornyl acrylate (IBA), and $\mathrm{R}=-\left(\mathrm{CH}_{2}\right)_{11} \mathrm{CH}_{3}$ for lauryl acrylate (LA).

cyclopentenone unit can potentially provide useful functionality for postpolymerization modification, transformation into other functionalities, or cross-linking (Scheme 1). For example, by making use of the $\alpha, \beta$ unsaturated ketone group of 4CPA, UV light can induce the coupling of pendent cyclopentenone units via a photodimerization reaction. Schiess and Suter have previously investigated the photocyclodimerization of 4oxocyclopent-2-en-1-yl acetate (1), the acetate of $4 \mathrm{HCP} .^{25}$ However, the aim of the investigation was to obtain the elimination products of the dimer. They found that with UVlight exposure of the pure compound, dimerization was in competition with homolytical cleavage of the acetoxy group. This was confirmed by performing the dimerization in ether, which yielded the solvent adduct of (1). In the molten state after $27 \mathrm{~h}$ irradiation with UV light, the head-to-tail (HT) dimer could be isolated with a yield of $9.5 \%$. The deacetylated head-tohead $(\mathrm{HH})$ and head-to-tail dimers were obtained with 32 and $26 \%$ yields, respectively. The ability of ( 1 ) to dimerize under UV light suggests that 4CPA-based polymers can be employed for photocuring applications. This serves as a potential route to biobased networks for film and coating applications.

In many cases, UV-curable polymers undergo network formation via a free radical mechanism. These systems make up the majority of the radiation curing market ${ }^{26}$ and usually require a photoinitiator, cross-linker, and reactive diluent depending on the method that is applied. Cross-linking via photodimerization of functional monomers proceeds readily with or without the addition of a photosensitizer and thus does not require any additional, often toxic additives such as initiators or cross-linkers to achieve network formation. Several functional groups that can undergo photocycloadditions have been incorporated in polymers, some of which include coumarin, ${ }^{27-30}$ cinnamic acid, ${ }^{31,32}$ conjugated furanes, ${ }^{33}$ or anthracene $^{34-37}$ groups.
When a functional monomer is polymerized directly to obtain functional polymers, as in the case of 4CPA, additional difficulties induced by the double bond in the ring can arise during free radical polymerization. For example, selectivity between functional groups is crucial in obtaining good control over the molecular weight. This was shown for the polymerization of divinyl monomers. ${ }^{38-40}$ If the difference in reactivity of the vinyl groups is not large enough, the participation of the pendent vinyl groups can cause cyclization, branching, or crosslinking reactions. One major strategy to reduce side reactions from the pendent vinyl group is to decrease the amount of the divinyl monomer via copolymerization with a monofunctional monomer. For the selective (co)polymerization of 4CPA, controlled radical polymerization (CRP) is applied. This way, molecular weight is limited to sufficiently short chains, so gel formation of the 4CPA (co)polymers is prevented. Reversible addition-fragmentation chain transfer (RAFT) polymerization is one of the major CRP techniques and provides a high tolerance to functional groups in the synthesis of well-defined polymers. $^{41}$

$4 \mathrm{HCP}$ is a versatile building block in organic chemistry, which makes it a promising monomer for functional polymers. In this work, 4CPA is proposed as a new biobased functional monomer, which can, after being incorporated in the polymer chain, undergo photocycloaddition reactions to generate networks. Because of the functionality of 4CPA, a selective CRP technique should be established for the preparation of well-defined polymers. Therefore, the synthesis of 4CPA-based homo- and copolymers with various biobased comonomers via RAFT polymerization is explored. The biobased comonomers that were used in this research can all be obtained by esterification of a biobased alcohol with acrylic acid (Scheme 1). The resulting monomers can be considered partially or potentially biobased, depending on the alcohol used. In addition, acrylic acid can be considered potentially renewable, ${ }^{42}$ but, currently, most acrylic 
acid is produced via the oxidation of propylene. ${ }^{43}$ The monomers used in this research are methyl acrylate (derived from methanol, obtained from the fermentation of sugars), isobornyl acrylate (derived from isoborneol, obtained from the reduction of camphor), and lauryl acrylate (derived from lauryl alcohol, obtained from hydrolysis and hydrogenation of natural oils). Additionally, 4-oxocyclopent-2-en-1-yl acetate was used as a model compound to obtain information on the 4CPA reactivity and dimerization in UV light. The latter reaction was confirmed experimentally by NMR and supported by quantum mechanical simulations. Furthermore, cross-linking and film formation under UV light of the 4CPA copolymers was followed by characterization with IR spectroscopy, dynamic mechanical analysis (DMA), dynamic scanning calorimetry (DSC), and swelling studies.

\section{EXPERIMENTAL SECTION}

2.1. Materials. Azobisisobutyronitrile (AIBN, Sigma-Aldrich) was recrystallized from methanol prior to use. Isobornyl acrylate (IBA; technical, Sigma-Aldrich) and lauryl acrylate (LA; >98\%, TCI) were passed over a basic alumina column prior to use to remove the stabilizer. Methyl acrylate (MA; 99\%, Sigma-Aldrich) was distilled prior to use. Pyridine, dichloromethane (DCM), and triethylamine were distilled over calcium hydride $\left(\mathrm{CaH}_{2}\right)$ prior to use. Cyanomethyl dodecyl trithiocarbonate $(\mathrm{CDT})$ was synthesized according to a procedure mentioned in the literature. ${ }^{44}$ 2-(Dodecylthiocarbonothioylthio)-2methylpropionic acid (DDMAT; 98\%, Sigma-Aldrich), trioxane ( $\geq 99 \%$, Sigma-Aldrich), biphenyl ( $>99 \%$, Sigma-Aldrich), acetophenone (AP; 99\%, Sigma-Aldrich), sodium sulfate ( $\geq 99 \%$, SigmaAldrich), acetic anhydride ( $\geq 99 \%$, Sigma-Aldrich), trans-2-[3-(4-tertbutylphenyl)-2-methyl-2-propenylidene]-malononitrile (DCTB; Sigma-Aldrich, >98\%), potassium trifluoroacetate (KTFA; SigmaAldrich, 98\%), acryloyl chloride (96\%, Alfa Aesar), furfuryl alcohol ( $\geq 98 \%$, Fischer Scientific), hydrogen chloride ( $\mathrm{HCl} ; 37 \%$ solution in $\mathrm{H}_{2} \mathrm{O}$, Acros Organics), sodium bicarbonate (>99\%, Acros organics), sodium chloride ( $\geq 99.8 \%$, Roth), tert-butyl methylether (TBME; 99.9\%), acetic acid (AcOH; 99.7\%), and $\mathrm{CDCl}_{3}$ (99.8\%, Cambridge Isotope Laboratories) were used as received. All other solvents were obtained from Biosolve and were used as received.

2.2. Instrumentation. Differential scanning calorimetry (DSC) (TA instruments, Qseries, DSC Q2000) with a heating rate of $10{ }^{\circ} \mathrm{C} /$ min was used to obtain information on the phase transition temperatures. Before DSC measurements, the samples were dried for $24 \mathrm{~h}$ at $50-80{ }^{\circ} \mathrm{C}$ in vacuum before measurements. The polymers were first subjected to a heating and cooling cycle. Then, the samples were heated at a scanning rate of $10{ }^{\circ} \mathrm{C} / \mathrm{min}$. The $T_{\mathrm{g}}$ of each polymer was determined as the temperature at the midpoint of the transition. Gel permeation chromatography (GPC) was performed at $30{ }^{\circ} \mathrm{C}$ using a Waters GPC equipped with a Waters 2414 refractive index detector. tetrahydrofuran (THF) was used as the eluent at a flow rate of $1 \mathrm{~mL} /$ min. Three linear columns (Styragel HR1, Styragel HR4, and Styragel HR5) including a Styragel Guard column were used. Molecular masses are given relative to polystyrene standards. The polymers were dissolved in THF with a concentration of $3 \mathrm{mg} / \mathrm{mL}$ and filtered over a $0.2 \mu \mathrm{m}$ PTFE syringe filter. ${ }^{1} \mathrm{H}$ NMR (300 MHz) and ${ }^{13} \mathrm{C}$ NMR (75 $\mathrm{MHz}$ ) spectra were recorded on a Bruker DPX-300 MHz apparatus at $298 \mathrm{~K}$ in $\mathrm{CDCl}_{3}$. For ${ }^{1} \mathrm{H}$ NMR measurements, 16 scans were used and for ${ }^{13} \mathrm{C}$ NMR measurements 1024 scans. ${ }^{1} \mathrm{H}$ NMR spectroscopy was used for the determination of monomer conversion in the homopolymerization of 4CPA, and the disappearance of the vinyl protons was followed over time relative to trioxane, which was added as an internal standard to the reaction mixture. Gas chromatography with flame ionization detection (GC-FID) measurements were performed on a Shimadzu GC-2010 equipped with a Supelco SPB-1 capillary column $(30 \mathrm{~m} \times 0.25 \mathrm{~mm} \times 0.25 \mu \mathrm{m}$ film thickness $)$. GC-FID was used to follow the disappearance of the individual monomers in the copolymerizations relative to biphenyl as the internal standard. The temperature program was as follows: an initial temperature of $80^{\circ} \mathrm{C}$ was maintained for $3 \mathrm{~min}$ and then increased to $140^{\circ} \mathrm{C}$ with a heating rate of $10{ }^{\circ} \mathrm{C} / \mathrm{min}$. This temperature was maintained for $1 \mathrm{~min}$ and further increased to $300{ }^{\circ} \mathrm{C}$ with a heating rate of $20{ }^{\circ} \mathrm{C} / \mathrm{min}$ and was maintained at $300{ }^{\circ} \mathrm{C}$ for $5 \mathrm{~min}$ (the total run time of $23 \mathrm{~min}$ ). Fourier transform infrared (FT-IR) spectra were recorded on a Shimadzu IRAffinity-1S FT-IR spectrometer. Samples were measured by applying a sample on the ATR crystal, and the spectra were recorded in the transmission mode between 400 and $4500 \mathrm{~cm}^{-1}$ and with 64 accumulations per spectrum. Dynamic mechanical analysis (DMA) was performed in a TA Instruments DMA Q800 to determine the viscoelastic behavior of the polymer networks (three samples per material). Rectangular samples $0.13-0.40 \mathrm{~mm}$ thick, $5.65-10 \mathrm{~mm}$ wide, and 10-12.1 mm long were measured in tension mode at a frequency of $1 \mathrm{~Hz}$, an oscillation strain of $0.05-0.1 \%$, a force tracking of $115-125 \%$, and a heating rate of $2{ }^{\circ} \mathrm{C} / \mathrm{min}$. The transition temperatures were determined at the intersection of the tangents of the storage modulus. The samples were dried beforehand for $24 \mathrm{~h}$ at 50 ${ }^{\circ} \mathrm{C}$ in vacuum. Electron impact mass spectrometry (MS) of the model dimer compound was recorded on a Shimadzu QP2010 ultra mass spectrometer using direct MS injection. The sample was heated to 350 ${ }^{\circ} \mathrm{C}$ with a heating rate of $20^{\circ} \mathrm{C} / \mathrm{min}$. Matrix-assisted laser desorption/ ionization time-of-flight mass spectra (MALDI-ToF-MS) were recorded on a Bruker UltrafleXtreme spectrometer with a $355 \mathrm{~nm}$ $\mathrm{Nd}$ :Yag laser $(2 \mathrm{kHz}$ repetition pulse/Smartbeam-II) and a grounded steel plate. DCTB was used as the matrix $(20 \mathrm{mg} / \mathrm{mL}$ in THF), and KTFA was used as a cationization agent $(10 \mathrm{mg} / \mathrm{mL}$ in THF). The polymers were dissolved in THF $(10 \mathrm{mg} / \mathrm{mL})$. Solutions of the matrix, salt, and polymer were mixed in volume ratios of 200:10:30, respectively. All mass spectra were recorded in the reflector mode. Poly(ethylene glycol) standards with $M_{\mathrm{n}}$ of 5000, 10000 , and $15000 \mathrm{~g} /$ mol were used for calibration. mMass was used to compare theoretical isotope distributions with experimental isotope distributions. Contour plots were generated using COCONUT version $1.5 .{ }^{45}$ Melting points were determined using a Mettler Toledo MP90 melting point system, and a heating rate of $10^{\circ} \mathrm{C} / \mathrm{min}$ was used.

2.3. Swelling Experiments. Swelling experiments were performed by immersing an accurately weighed sample of approximately $50 \mathrm{mg}$ into $5 \mathrm{~mL}$ of chloroform for $24 \mathrm{~h}$ at room temperature. The swollen solids were weighed and then filtered and dried for $24 \mathrm{~h}$ at $50{ }^{\circ} \mathrm{C}$ in vacuum. All swelling experiments were performed in triplicate.

The soluble fraction and swell ratio were calculated accordingly

$$
\begin{aligned}
& \text { soluble fraction }=\left(m_{\text {initial }}-m_{\text {dry }}\right) / m_{\text {initial }} \\
& \text { swell ratio }=\left(m_{\text {swollen }}-m_{\text {initial }}\right) / m_{\text {initial }}
\end{aligned}
$$

2.4. 4-Hydroxycyclopent-2-en-1-one (4HCP) Synthesized in Flow. ${ }^{46}$ A solution of furfuryl alcohol $(25.0 \mathrm{~g}, 255 \mathrm{mmol})$ in water (500 $\mathrm{mL}$ ) was adjusted with $\mathrm{AcOH}$ to $\mathrm{pH}=4$ and heated in a flow reactor consisting of a stainless steel coil of 6 meters with a back-pressure regulator at $240{ }^{\circ} \mathrm{C}$ (flow pump $5 \mathrm{~mL} / \mathrm{min}$ of solution per min and 0.3 $\mathrm{mL}$ of toluene per $\mathrm{min})$. After completion, the mixture was extracted with TBME $(3 \times 30 \mathrm{~mL})$ and the water layer was concentrated under reduced pressure. The crude yield was not determined. The reaction was scaled up to $10 \mathrm{~L}$ reaction volume. The crude product $(150 \mathrm{~g}$ of the material from several batches) was purified using a vacuum jacketed Vigreux of $30 \mathrm{~cm}$ (heating bath: $130{ }^{\circ} \mathrm{C}$, pressure: $0.001 \mathrm{mbar}$, distillation temperature: $90{ }^{\circ} \mathrm{C}$ ), yielding the title compound as an almost colorless oil, which was stored in a freezer at $-20^{\circ} \mathrm{C}$. Yield: $50 \mathrm{~g}$. ${ }^{1} \mathrm{H}$ NMR $\left(300 \mathrm{MHz}, \mathrm{CDCl}_{3}\right): \delta(\mathrm{ppm})=2.19-2.82\left(\mathrm{~m}, 2 \mathrm{H}, \mathrm{CH}_{2}\right)$; $2.98(\mathrm{~s}, 1 \mathrm{H}, \mathrm{OH}) ; 5.02(\mathrm{~m}, 1 \mathrm{H}, \mathrm{CH}-\mathrm{OH}) ; 6.20(\mathrm{~d}, 1 \mathrm{H}, \mathrm{CH}-\mathrm{C}=\mathrm{O})$; 7.57 (dd, $1 \mathrm{H}, \mathrm{CH}-\mathrm{C}-\mathrm{O}) .{ }^{13} \mathrm{C} \mathrm{NMR}\left(75 \mathrm{MHz}, \mathrm{CDCl}_{3}\right): \delta(\mathrm{ppm})=$ $44.4\left(\mathrm{CH}_{2}\right) ; 70.5(\mathrm{CH}-\mathrm{OH}) ; 135.1(\mathrm{CH}-\mathrm{C}=\mathrm{O}) ; 163.7(\mathrm{CH}-\mathrm{C}-$ $\mathrm{O}) ; 207.2(\mathrm{C}=\mathrm{O}) .{ }^{1} \mathrm{H}$ NMR and ${ }^{13} \mathrm{C}$ NMR spectra are shown in Figure S7.

2.5. Synthesis of 4-Oxocyclopent-2-en-1-yl Acrylate (4CPA). 4-Hydroxycyclopent-2-en-1-one ( $85.8 \mathrm{~g}$, 1 equiv, $0.875 \mathrm{~mol}$ ) was dissolved in DCM $(860 \mathrm{~mL})$ and cooled with an ice-water bath to $0{ }^{\circ} \mathrm{C}$. Triethylamine (106 g, $145 \mathrm{~mL}, 1.20$ equiv, $1.05 \mathrm{~mol}$ ) was added, followed by the slow addition of acryloyl chloride $(87.1 \mathrm{~g}, 78.2 \mathrm{~mL}, 1.10$ equiv, $0.962 \mathrm{~mol})$. The temperature was kept below $18{ }^{\circ} \mathrm{C}$ during the 
addition. After the addition was completed, stirring was continued for $5.5 \mathrm{~h}$ at a temperature between 16 and $18{ }^{\circ} \mathrm{C}$. TBME $(1200 \mathrm{~mL})$ was added. The solids were removed by filtration over a thin layer of silica gel and washed with TBME $(800 \mathrm{~mL})$. The yellow filtrate was concentrated under reduced pressure at $35^{\circ} \mathrm{C}$ and redissolved in DCM. The organic layer was washed with $0.5 \mathrm{~N} \mathrm{HCl}, \mathrm{NaHCO}_{3}$, water, and finally brine (twice). The organic layer was dried over $\mathrm{Na}_{2} \mathrm{SO}_{4}$, filtered, and concentrated under reduced pressure. The crude material was purified by vacuum distillation (bath temperature: $100{ }^{\circ} \mathrm{C}$, pressure: $10^{-3} \mathrm{mbar}$, bp: $60^{\circ} \mathrm{C}$ ). $4 \mathrm{CPA}$ was isolated as a slightly yellow oil. Yield: $111.6 \mathrm{~g}(84 \%) .{ }^{1} \mathrm{H} \mathrm{NMR}\left(300 \mathrm{MHz}, \mathrm{CDCl}_{3}\right): \delta(\mathrm{ppm})=2.31-2.91(\mathrm{~m}$, $\left.2 \mathrm{H}, \mathrm{CH}_{2}-\mathrm{C}=\mathrm{O}\right) ; 5.89\left(\mathrm{dd}, 1 \mathrm{H}, \mathrm{CH}_{2}=\mathrm{CH}\right) ; 5.91-5.96(\mathrm{~m}, 1 \mathrm{H}$, $\mathrm{CH}-\mathrm{O}) ; 6.05-6.18\left(\mathrm{~m}, 1 \mathrm{H}, \mathrm{CH}=\mathrm{CH}_{2}\right) ; 6.34(\mathrm{dd}, 1 \mathrm{H}, \mathrm{CH}-\mathrm{C}=\mathrm{O})$; 6.44 (dd, $\left.1 \mathrm{H}, \mathrm{CH}_{2}=\mathrm{CH}\right) ; 7.59$ (dd, $\left.1 \mathrm{H}, \mathrm{CH}-\mathrm{C}-\mathrm{O}\right) .{ }^{13} \mathrm{C} \mathrm{NMR}(75$ $\left.\mathrm{MHz}, \mathrm{CDCl}_{3}\right): \delta(\mathrm{ppm})=40.1\left(\mathrm{CH}_{2}-\mathrm{C}=\mathrm{O}\right) ; 72.2(\mathrm{C}-\mathrm{O}) ; 127.8$ $\left(\mathrm{CH}=\mathrm{CH}_{2}\right) ; 132.1\left(\mathrm{CH}_{2}=\mathrm{CH}\right) ; 137.2(\mathrm{CH}-\mathrm{C}=\mathrm{O}) ; 159.0(\mathrm{CH}-$ $\mathrm{C}-\mathrm{O}) ; 165.6\left(\mathrm{C}=\mathrm{O}_{\text {acrylate }}\right) ; 204.9\left(\mathrm{C}=\mathrm{O}_{\text {cyclopentenone }}\right) .{ }^{1} \mathrm{H}$ NMR and ${ }^{13} \mathrm{C}$ NMR spectra are shown in Figure $\mathrm{S} 8$.

2.6. Model Compound 4-Oxocyclopent-2-en-1-yl Acetate (1). It was synthesized according to a procedure previously reported in the literature ${ }^{47}$ (Figure 1).

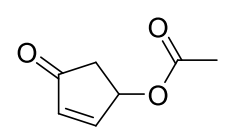

Figure 1. Chemical structure of 4-oxocyclopent-2-en-1-yl acetate (1).

In summary, the synthesis was as follows. A $100 \mathrm{~mL}$ two-neck roundbottom flask was charged with 4HCP $(5.0 \mathrm{~g}, 51 \mathrm{mmol}, 1$ equiv). The flask was evacuated and flushed with nitrogen. Dry DCM $(50 \mathrm{~mL})$ was added, and the mixture was cooled to $0{ }^{\circ} \mathrm{C}$ using an ice bath. Dry pyridine $(7.9 \mathrm{~g}, 100 \mathrm{mmol}, 2$ equiv) was added to the cold solution while stirring with a magnetic stirrer. To the mixture, acetic anhydride ( $7.8 \mathrm{~g}, 76.5 \mathrm{mmol}, 1.5$ equiv) was added dropwise while maintaining the temperature at $0{ }^{\circ} \mathrm{C}$. After the complete addition of the acetic anhydride, the reaction mixture was allowed to warm to room temperature and was stirred for $15 \mathrm{~h}$. The reaction was quenched by adding cold, dilute $\mathrm{HCl}$. The organic layer was washed with dilute $\mathrm{HCl}$, followed by water, $\mathrm{NaHCO}_{3}$, and finally with brine. The organic layer was dried over $\mathrm{Na}_{2} \mathrm{SO}_{4}$, and the solvent was evaporated under vacuum. The residue was purified by vacuum distillation (bp $60{ }^{\circ} \mathrm{C}$ at $10^{-3}$ mbar). (1) was obtained as a light-yellow oil, which crystallized upon cooling. Yield: $4.39 \mathrm{~g}(62 \%)$. Melting point: $35{ }^{\circ} \mathrm{C} .{ }^{1} \mathrm{H}$ NMR $(300$ $\left.\mathrm{MHz}, \mathrm{CDCl}_{3}\right): \delta(\mathrm{ppm})=2.08\left(\mathrm{~s}, 3 \mathrm{H}, \mathrm{CH}_{3}\right) ; 2.25-2.87\left(\mathrm{~m}, 2 \mathrm{H}, \mathrm{CH}_{2}\right)$; $5.84(\mathrm{~m}, 1 \mathrm{H}, \mathrm{CH}-\mathrm{O}) ; 6.32(\mathrm{dd}, 1 \mathrm{H}, \mathrm{CH}-\mathrm{C}=\mathrm{O}) ; 7.56(\mathrm{dd}, 1 \mathrm{H}, \mathrm{CH}-$ $\mathrm{CH}-\mathrm{O}) .{ }^{13} \mathrm{C} \mathrm{NMR}\left(75 \mathrm{MHz}, \mathrm{CDCl}_{3}\right): \delta(\mathrm{ppm})=21.0\left(\mathrm{CH}_{3}\right) ; 41.1$ $\left(\mathrm{CH}_{2}\right) ; 72.0(\mathrm{CH}-\mathrm{O}) ; 137.1(\mathrm{CH}-\mathrm{C}=\mathrm{O}) ; 159.1(\mathrm{CH}-\mathrm{CH}-\mathrm{O})$; $170.5\left(\mathrm{C}=\mathrm{O}_{\text {acetate }}\right) ; 205.0\left(\mathrm{C}=\mathrm{O}_{\text {cyclopentenone }}\right) .{ }^{1} \mathrm{H}$ NMR and ${ }^{13} \mathrm{C}$ NMR spectra are shown in Figure S9.

2.7. Photodimerization of (1). A solution of (1) ( $386 \mathrm{mg}, 2.76$ $\mathrm{mmol})$ was prepared in acetone $(5 \mathrm{~mL})$. The mixture was irradiated using a $400 \mathrm{~W}$ metal halide, UVA lamp in a Dymax ECE $2000 \mathrm{UV}$ chamber under a nitrogen flow. Inside the chamber, the solution reached a maximum temperature of approximately $40{ }^{\circ} \mathrm{C}$. The disappearance of (1) was followed by gas chromatography. After 230 min, irradiation was stopped and excess acetone was evaporated under reduced pressure. The viscous liquid was extracted with diethyl ether, from which white crystals precipitated at $-20{ }^{\circ} \mathrm{C}$. Yield: $71.3 \mathrm{mg}$ (18.4\%). Melting point: $81^{\circ} \mathrm{C} .{ }^{1} \mathrm{H}$ NMR $\left(300 \mathrm{MHz}, \mathrm{CDCl}_{3}\right): \delta(\mathrm{ppm})$ $=2.00\left(\mathrm{~s}, 3 \mathrm{H}, \mathrm{CH}_{3}\right) ; 2.11\left(\mathrm{~s}, 3 \mathrm{H}, \mathrm{CH}_{3}\right) ; 2.43-3.16\left(\mathrm{~m}, 8 \mathrm{H}, \mathrm{CH}_{2}\right.$, $\left.\mathrm{CH}_{\text {cyclobutane }}\right) ; 5.32(\mathrm{~d}, 1 \mathrm{H}, \mathrm{CH}-\mathrm{O}) ; 5.43(\mathrm{q}, 1 \mathrm{H}, \mathrm{CH}-\mathrm{O}) .{ }^{13} \mathrm{C}$ NMR $\left(75 \mathrm{MHz}, \mathrm{CDCl}_{3}\right): \delta(\mathrm{ppm})=20.9\left(\mathrm{CH}_{3}\right) ; 21.1\left(\mathrm{CH}_{3}\right) ; 40.4(\mathrm{CH})$; $41.9\left(\mathrm{CH}_{2}\right) ; 42.6\left(\mathrm{CH}_{2}\right) ; 42.9(\mathrm{CH}) ; 43.8(\mathrm{CH}) ; 45.9(\mathrm{CH}) ; 70.0$ $(\mathrm{CH}-\mathrm{O}) ; 75.1(\mathrm{CH}-\mathrm{O}) ; 170.0\left(\mathrm{C}=\mathrm{O}_{\text {acetate }}\right) ; 170.2\left(\mathrm{C}=\mathrm{O}_{\text {acetate }}\right)$; $212.7\left(\mathrm{C}=\mathrm{O}_{\text {ring }}\right) ; 213.5\left(\mathrm{C}=\mathrm{O}_{\text {ring }}\right)$. $\mathrm{MS}$ for $\mathrm{C}_{14} \mathrm{H}_{16} \mathrm{O}_{6}: m / z=280 \mathrm{~g} /$ $\mathrm{mol}($ calcd $280.09 \mathrm{~g} / \mathrm{mol})$.

2.8. Homopolymerization of 4CPA. In a typical experiment, 4CPA was polymerized using CDT as the RAFT agent (Table 1 , entry 3). 4CPA ( $500 \mathrm{mg}, 3.29 \mathrm{mmol}, 500$ equiv), AIBN ( $1.1 \mathrm{mg}, 0.0066$ mmol, 1 equiv), CDT (10.4 mg, $0.033 \mathrm{mmol}, 5$ equiv), dimethylformamide (DMF) $(2 \mathrm{~mL})$, and trioxane (5 wt \% relative to monomer) were added to a $5 \mathrm{~mL}$ Schlenk flask equipped with a magnetic stir bar. The mixture was degassed by at least three consecutive freeze-pump-thaw cycles. The flask was immersed in a thermostated oil bath at $70^{\circ} \mathrm{C}$. During the reaction, samples were taken at several time intervals for ${ }^{1} \mathrm{H}$ NMR spectroscopy to check the monomer conversion. After $5 \mathrm{~h}$, the polymerization was quenched by cooling to room temperature and diluting with THF. The polymer was precipitated twice in a 20 -fold excess of methanol and dried at $70{ }^{\circ} \mathrm{C}$ under vacuum for $24 \mathrm{~h}$.

2.9. Copolymerization of 4CPA with Biobased Comonomers. All copolymerizations were performed under the same conditions; a 40 wt \% monomer concentration in the solvent was maintained for all monomers. In the following experiment, poly(4CPA-co-LA) with $30 \%$ 4CPA incorporation (P3-3/7 in Table 2) was prepared. 4CPA (4.0 g, $26.3 \mathrm{mmol}, 150$ equiv), LA (14.8 g, $61.4 \mathrm{mmol}, 350$ equiv), AIBN (29 $\mathrm{mg}, 0.175 \mathrm{mmol}, 1$ equiv), CDT ( $278 \mathrm{mg}, 0.877 \mathrm{mmol}, 5$ equiv), DMF $(29.8 \mathrm{~mL})$, and biphenyl ( $5 \mathrm{wt} \%$ relative to monomers) were added to a $100 \mathrm{~mL}$ Schlenk flask equipped with a magnetic stir bar. The solution was degassed by at least three consecutive freeze-pump-thaw cycles. The flask was then immersed in a thermostated oil bath at $70{ }^{\circ} \mathrm{C}$. Samples were taken at several time intervals for GPC to check the molecular weight development and for GC-FID analysis to track the individual monomer conversions. After $6 \mathrm{~h}$, the reaction was stopped by cooling the mixture to room temperature and diluting with THF. The overall monomer conversion at this point was $71.8 \%$. The polymer was precipitated twice in $800 \mathrm{~mL}$ methanol and dried at $60{ }^{\circ} \mathrm{C}$ under vacuum. A yellow viscous polymer was obtained. Yield: $12.75 \mathrm{~g}$ (68.0\%).

2.10. Photo-Cross-Linking. Polymer films were prepared by dissolving $300 \mathrm{mg}$ of a copolymer (P2-3/7 or P3-3/7 in Table 2) in 3 $\mathrm{mL}$ of chloroform, with or without the addition of the acetophenone photosensitizer. The solutions were cast on quartz glass slides $(50 \times 70$ $\mathrm{mm}$ ), and the solvent was allowed to evaporate for at least $1 \mathrm{~h}$. The film

\section{Table 1. RAFT Homopolymerization of 4CPA}

\begin{tabular}{|c|c|c|c|c|c|c|c|c|c|}
\hline entry & CTA & {$[\mathrm{I}] /[\mathrm{CTA}] /[\mathrm{M}]$} & time (min) & solvent & 4CPA concn (wt \%) & $\operatorname{conv}_{\mathrm{NMR}}(\%)$ & $M_{\mathrm{n}, \mathrm{th}}{ }^{d}(\mathrm{~kg} / \mathrm{mol})$ & $M_{\mathrm{n}, \mathrm{GPC}}{ }^{a}(\mathrm{~kg} / \mathrm{mol})$ & $\boxplus^{a}$ \\
\hline 1 & CDT & $1 / 5 / 100$ & 2760 & toluene & 20 & c & $c$ & c & $c$ \\
\hline 2 & CDT & $1 / 5 / 100$ & 330 & DMF & 20 & 71.8 & 2.5 & 3.9 & 1.18 \\
\hline 3 & $\mathrm{CDT}$ & $1 / 5 / 500$ & 305 & DMF & 20 & 45.2 & 7.2 & 6.6 & 1.25 \\
\hline 4 & $\mathrm{CDT}$ & $1 / 5 / 500$ & 90 & DMF & 60 & 51.2 & $b$ & $b$ & $b$ \\
\hline 5 & $\mathrm{CDT}$ & $1 / 5 / 100$ & 60 & none & bulk & 89.7 & 3.7 & 8.6 & 7.96 \\
\hline 6 & DDMAT & $1 / 5 / 500$ & 360 & DMF & 20 & 19.0 & 3.3 & 4.4 & 1.08 \\
\hline 7 & DDMAT & $1 / 5 / 500$ & 140 & DMF & 60 & 29.6 & 4.9 & 6.0 & 1.13 \\
\hline 8 & DDMAT & $1 / 5 / 100$ & 150 & none & bulk & 57.2 & 2.1 & 4.4 & 1.12 \\
\hline
\end{tabular}

${ }^{a}$ Determined by THF GPC against polystyrene standards, the results are of the final polymer after precipitation in methanol. ${ }^{b}$ Polymer formed a gel at higher conversions. ${ }^{c}$ Polymer precipitated in the reaction solvent. ${ }^{d}$ Calculated from $M_{\mathrm{n}, \mathrm{th}}=\mathrm{MW}_{\mathrm{CTA}}+\left(\mathrm{DP}_{\mathrm{n}, \mathrm{th}} \times \%\right.$ conversion $_{4 \mathrm{CPA}} \times 152.1 \mathrm{~g} /$ $\mathrm{mol})$. 
Table 2. RAFT Copolymerization of 4CPA with IBA, MA, and LA

\begin{tabular}{|c|c|c|c|c|c|c|c|c|c|c|}
\hline code & comonomer & $\mathrm{f}_{4 \mathrm{CPA}}$ & $\mathrm{F}_{4 \mathrm{CPA}}{ }^{c}$ & conv $4 \mathrm{CPA}(\%)$ & conv comonomer (\%) & $M_{\mathrm{n}, \mathrm{th}}^{e}(\mathrm{~kg} / \mathrm{mol})$ & $M_{\mathrm{n}, \mathrm{GPC}}{ }^{a}(\mathrm{~kg} / \mathrm{mol})$ & $\boxplus^{a}$ & $T_{\mathrm{g}}\left({ }^{\circ} \mathrm{C}\right)$ & $T_{\mathrm{m}}\left({ }^{\circ} \mathrm{C}\right)$ \\
\hline P1-6/4 & IBA & 0.60 & 0.62 & 64 & 56 & 10.8 & 13.1 & 7.46 & 80 & \\
\hline $\mathrm{P} 1-5 / 5$ & IBA & 0.50 & 0.51 & 69 & 61 & 11.9 & 12.8 & 2.21 & 87 & \\
\hline P1-4/6 & IBA & 0.40 & 0.42 & 67 & 59 & 11.8 & 9.6 & 1.34 & 89 & \\
\hline $\mathrm{P} 1-3 / 7$ & IBA & 0.30 & 0.32 & 71 & 63 & 12.7 & 11.0 & 1.27 & 88 & \\
\hline $\mathrm{P} 1-2 / 8$ & IBA & 0.20 & 0.20 & 78 & 71 & 14.5 & 11.8 & 1.33 & 92 & \\
\hline $\mathrm{P} 1-1 / 9$ & IBA & 0.10 & 0.09 & 71 & 64 & 13.4 & 8.3 & 1.26 & 96 & \\
\hline $\mathrm{P} 2-5 / 5$ & MA & 0.50 & 0.54 & 81 & 80 & 9.9 & 19.2 & 7.94 & 55 & \\
\hline $\mathrm{P} 2-4 / 6$ & MA & 0.40 & 0.42 & 81 & 76 & 9.2 & 13.2 & 2.57 & 46 & \\
\hline $\mathrm{P} 2-3 / 7$ & MA & 0.30 & 0.30 & 86 & 82 & 9.2 & 12.4 & 1.44 & 36 & \\
\hline $\mathrm{P} 2-2 / 8$ & MA & 0.20 & 0.26 & 90 & 86 & 9.0 & 13.8 & 1.78 & 35 & \\
\hline $\mathrm{P} 2-1 / 9$ & MA & 0.10 & 0.11 & 95 & 91 & 8.8 & 9.2 & 1.19 & 17 & \\
\hline P3-6/4 & LA & 0.60 & 0.62 & 67 & 59 & 12.1 & 14.7 & 5.85 & 21 & \\
\hline $\mathrm{P} 3-5 / 5$ & LA & 0.50 & 0.51 & 65 & 57 & 12.1 & 12.6 & 1.17 & 12 & \\
\hline P3-4/6 & LA & 0.40 & 0.39 & 73 & 67 & 14.1 & 14.0 & 1.30 & -2 & \\
\hline $\mathrm{P} 3-3 / 7$ & LA & 0.30 & 0.29 & 63 & 57 & 12.8 & 11.2 & 1.25 & $d$ & $d$ \\
\hline $\mathrm{P} 3-2 / 8$ & LA & 0.20 & 0.19 & 71 & 67 & 15.4 & 13.8 & 1.30 & $b$ & -3 \\
\hline
\end{tabular}

${ }^{a}$ Determined by THF GPC against polystyrene standards, the results are of the final polymer after precipitation in methanol. ${ }^{b}$ Not observed. ${ }^{c}$ Determined with ${ }^{1} \mathrm{H}$ NMR. ${ }^{d}$ Glass transition and the melting peak overlap in the DSC. ${ }^{e}$ Calculated from $M_{\mathrm{n}, \mathrm{th}}=317.58 \mathrm{~g} / \mathrm{mol}^{e}+(\mathrm{DP}$, th,4CPA$\times \%$ $\left.\operatorname{conv}_{4 \mathrm{CPA}} / 100 \times 152.1 \mathrm{~g} / \mathrm{mol}\right)+\left(\mathrm{DP}_{\mathrm{n}, \mathrm{th}, \mathrm{comonomer}} \times \% \operatorname{conv}_{\text {comonomer }} / 100 \times \mathrm{MW}_{\text {comonomer }}\right)$.

was placed in a Dymax ECE 2000 UV chamber under a nitrogen flow and irradiated using a $400 \mathrm{~W}$ metal halide, UVA lamp. The distance of the sample to the lamp was $18 \mathrm{~cm}$. The film was irradiated for $30 \mathrm{~min}$ on each side.

2.11. Computational Methods. To elucidate the experimental observations, four conformers of the dimers of (1) were modeled using quantum mechanical simulations. In these conformers, the acetate groups had either a head-to-head $(\mathrm{HH})$ or a head-to-tail (HT) configuration. Furthermore, the full dimers had a boat (b) or chair (c) configuration. The resulting four conformers are indicated as head-tohead chair ( $\mathrm{HHc})$, head-to-head boat $(\mathrm{HHb})$, head-to-tail chair $(\mathrm{HTc})$, and head-to-tail boat (HTb), and shown in Figure 2.

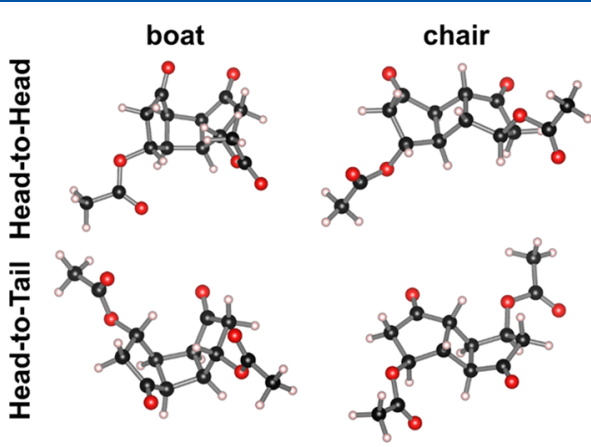

Figure 2. Ball-and-stick representation of the optimized dimer conformers. Top-left: head-to-head boat ( $\mathrm{HHb})$, top-right: head-tohead chair $(\mathrm{HHc})$, bottom-left: head-to-tail boat ( $\mathrm{HTb})$, and bottomright: head-to-tail chair $(\mathrm{HTc})$. The atomic structure is provided in Supporting Information (SI) and available as CCDC 19607681960772.

Spin-polarized first-principles simulations were performed within the density functional theory framework (DFT), as implemented in the Vienna ab initio simulation package. ${ }^{48,49}$ The exchange and correlation behavior of the valence electrons was described using the generalized gradient method as derived by Perdew, Burke, and Ernzerhof (PBE).$^{50}$ Dispersion interactions were incorporated using the DFT-D3 method. ${ }^{51}$ To obtain more accurate NMR parameters, the hard version of the projector-augmented wave (PAW) potentials was used during all calculations. A vacuum region of about $15 \AA$ was incorporated in each direction to reduce the interaction between periodic copies. All models were optimized using a kinetic energy cutoff of $800 \mathrm{eV}$ and an energy convergence criterion of $1.0 \times 10^{-7}$, resulting in final forces on each atom of $<2.0 \mathrm{meV} / \AA$. The Hessian matrix of the optimized structures was determined and used, after projecting out the translational and rotational modes (Figure S2), to verify the (local) energy minimum and to generate the vibrational spectrum. The temperature-dependent vibrational energy contributions were calculated from the latter using the HIVE toolbox. ${ }^{52,53}$ Atomic charges were calculated using the Hirshfeld-I partitioning scheme. ${ }^{54,55}$ The integration grid consisted of spherical Lebedev-Laikov grids of 1202 grid points and a logarithmic radial grid, with the convergence precision set to $1.0 \times 10^{-5}$. $.6,5756,57$ The chemical shifts were calculated using the linear response method developed by Yates, Pickard, and Mauri. ${ }^{58,59}$ To improve the accuracy, the two-center contributions were included and the small B-component of the wave function inside the PAW spheres was restored. ${ }^{60}$ For the calculation of the chemical shifts, the kinetic energy cutoff was increased to $1500 \mathrm{eV}$ and the energy convergence criterion was increased to $1.0 \times 10^{-10}$. With these settings, the chemical shift is expected to be converged to $0.1 \mathrm{ppm}$ and below $0.01 \mathrm{ppm}$ for $\mathrm{C}$ and $\mathrm{H}$, respectively.

\section{RESULTS AND DISCUSSION}

\subsection{Reactivity Study toward the Internal Double Bond} of 4CPA. The 4CPA polymerizability was studied using the model compound 4-oxocyclopent-2-en-1-yl acetate (1). As mentioned in the Introduction section, the internal double bond in 4CPA can participate during the polymerization of the acrylate, eventually leading to gelation of the polymer. To evaluate the reactivity of the internal double bond in the cyclopentenone unit, model compound (1) was subjected to RAFT polymerization conditions as described for the homopolymerization of 4CPA in Experimental Section. No conversion of (1) could be observed in GC-FID and ${ }^{1} \mathrm{H}$ NMR spectroscopy analysis after $6 \mathrm{~h}$ at $70{ }^{\circ} \mathrm{C}$. The inability of homopolymerization of $(1)$ can be attributed to steric effects. It is known that 1,2-disubstituted alkenes are challenging to homopolymerize; however, copolymerization can proceed quite readily. ${ }^{61}$ This result suggests that cyclization, branching, or cross-linking reactions by coupling of the pendent cyclopentenone units in the given polymerization conditions of 4CPA are unlikely to take place. Nevertheless, participation in the radical polymerization of the enone unit by propagation in the presence of acrylates is not ruled out. 
To further investigate the reactivity of (1), the model compound was copolymerized with $4 \mathrm{CPA}$ using $\mathrm{CDT}$ as the chain transfer agent in DMF at $70{ }^{\circ} \mathrm{C}$, with $[\mathrm{AIBN}]_{0} /[\mathrm{CDT}]_{0} /$ $[4 \mathrm{CPA}]_{0} /[(\mathbf{1})]_{0}=1: 5: 250: 250$. Samples were taken at several time intervals for MALDI-ToF-MS analysis. In Figure S10, the MALDI-ToF-MS spectrum, obtained after $50 \mathrm{~min}$ and $14 \%$ 4CPA conversion, is shown. The conversion was kept low to avoid gel formation or extensive branching of the polymer and reduce the effects of changing monomer composition. In the MALDI-ToF-MS spectrum, several polymeric distributions can be observed, with the main distribution belonging to the 4CPA homopolymer (Figure S10b). Interestingly, the largest distribution did not contain RAFT agent end groups but instead possessed hydrogen- or double-bond end groups resulting from termination and transfer processes. Most of the other smaller distributions could be assigned as copolymers of 4CPA and (1) containing one or two units of (1). Due to a large amount of different distributions observed in MALDI-ToF-MS of copolymers, full characterization of the polymer can be challenging. This is made more convenient by converting the onedimensional spectra into two-dimensional contour plots. The contour plot of the copolymerization of 4CPA and (1) is shown in Figure 3 and gives an indication of the copolymer

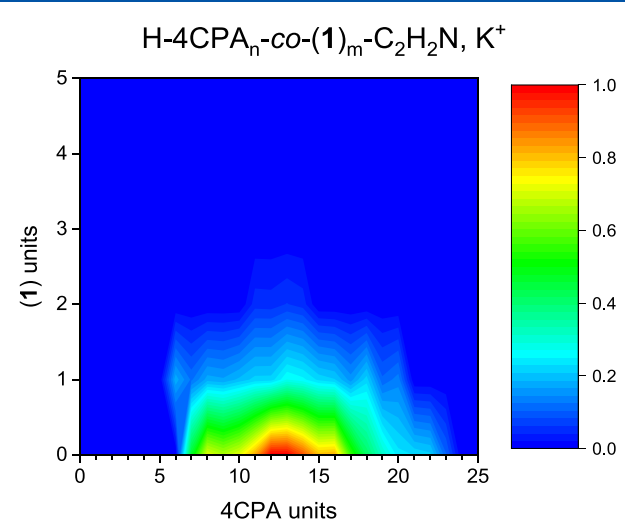

Figure 3. MALDI-ToF-MS contour plot of the copolymer H-4CPA ${ }_{n}^{-}$ co- $(1)_{m}-\mathrm{C}_{2} \mathrm{H}_{2} \mathrm{~N}, \mathrm{~K}^{+}$formed after $50 \mathrm{~min}$ during the RAFT copolymerization of 4CPA and (1) in a 50:50 ratio.

composition based on the position and shape of the distribution. In this case, the distribution is strongly located toward the $x$-axis, which indicates the amount of 4CPA units incorporated in the chain. The tendency toward incorporation of 4CPA and (1) into the polymer chains is strongly in favor of 4CPA, which is mainly attributed to the differences in stability of the formed radical and steric influences of the side groups of the reactive double bonds. Since some chains did contain incorporation of (1) at low conversion, gelation in the homopolymerization of 4CPA is expected to occur at high conversions and/or degree of polymerization (DP), since only a few linkages between polymer chains are enough to cause gel formation in the material.

3.2. Homopolymerization of 4CPA. In the selective homopolymerization of the acrylate group of 4CPA, several reaction conditions were varied to observe the effect on the molecular weight and conversion. Experiments were performed at $70{ }^{\circ} \mathrm{C}$, using AIBN as the thermal initiator, and two different RAFT agents were investigated: DDMAT and CDT. The results are summarized in Table 1 . During the polymerization, aliquots were withdrawn from the solution at several time intervals. Samples were analyzed by ${ }^{1} \mathrm{H}$ NMR spectroscopy and GPC to determine the conversion and molecular weight, respectively. Monomer conversion was determined by comparing the acrylate protons at 5.93, 6.1, and $6.34 \mathrm{ppm}$ (Figure S8a) with the signal from trioxane at $5.14 \mathrm{ppm}$, which was added as an internal standard.

The free radical polymerization of alkyl acrylates typically leads to extensive branching and gel formation, even at low monomer conversions due to inter- and intramolecular (i.e., backbiting) chain transfer reactions to the polymer. ${ }^{62}$ However, it has been shown that radicals exhibit an enhanced selectivity in the presence of a reversible deactivation process (i.e., RAFT polymerization) and transfer to polymer reactions is suppressed. This is related to the time of radical deactivation, which is typically shorter than the time of backbiting for a RAFT agent with a sufficiently high chain transfer constant. ${ }^{63}$ Indeed, initial studies toward the free radical polymerization of 4CPA yielded an insoluble gel quickly after the reaction temperature was reached. Therefore, RAFT polymerization was employed for the synthesis of poly (4CPA) homopolymers without gel formation. With the selection of a suitable chain transfer agent, RAFT is a convenient technique for the controlled polymerization of alkyl acrylates.

Initially, toluene was selected as the solvent (entry 1, Table 1); however, the polymer was not soluble and precipitated during the reaction. Therefore, the solvent was changed to DMF, which was a suitable solvent for the homopolymerization of 4CPA. With $[\mathrm{AIBN}]_{0} /[\mathrm{CDT}]_{0} /[4 \mathrm{CPA}]_{0}=1 / 5 / 100 \mathrm{in} \mathrm{DMF}$ at $20 \mathrm{wt}$ $\%$ monomer concentration (entry 2 , Table 1 ), a monomer conversion of $71.8 \%$ was reached, while the dispersity was only 1.18. This promising result indicates that competition of the internal double bond is limited, even at a reasonable high conversion. However, the targeted DP of this experiment is only 20 . In an attempt to increase the DP with $[\mathrm{AIBN}]_{0} /[\mathrm{CDT}]_{0} /$ $[4 \mathrm{CPA}]_{0}=1 / 5 / 500$ (entry 3 , Table 1 ) a lower monomer conversion was obtained, but the molecular weight was increased from 3.9 to $6.6 \mathrm{~kg} / \mathrm{mol}$, while the dispersity remained low at 1.25 . Improving the conversion by increasing the monomer concentration from 20 to 60 and 100\% (entries 3, 4 , and 5, Table 1) resulted in gel formation above $50 \%$ conversion when a DP of 100 was targeted. Given the low rate coefficients for intermolecular chain transfer reactions (which cause gel formation in acrylates) relative to intramolecular chain transfer reactions, ${ }^{64}$ gel formation at elevated conversion is unlikely caused by chain transfer to polymer processes but mainly due to contribution of the pendent cyclopentenone unit of 4CPA. Secondary reactions involving the cyclopentenone unit can take place because a resonance-stabilized radical can be formed on the ring due to the presence of the enone group. In our case, the low conversions that were obtained for some of the reactions could also be explained by termination and transfer reactions, which were observed in the copolymerization of 4CPA with (1) using MALDI-ToF-MS (Figure S10).

Under the same conditions as Table 1 , entry 3, the RAFT agent was changed to DDMAT, which resulted in a decrease in the monomer conversion from 45.2 to $19 \%$ (entry 6, Table 1). Similarly, when the reaction was performed at higher concentrations (entry 4 vs 7, Table 1 ) or in bulk (entry 5 vs 8), a lower monomer conversion was reached with DDMAT compared to CDT, which could, however, prevent gel formation. In Figure 4, the first-order kinetics of the polymerization with both RAFT agents is shown. A faster reaction rate is observed for CDT compared to that for DDMAT. Since both RAFT agents have the same trithiocarbonate Z-group, which 


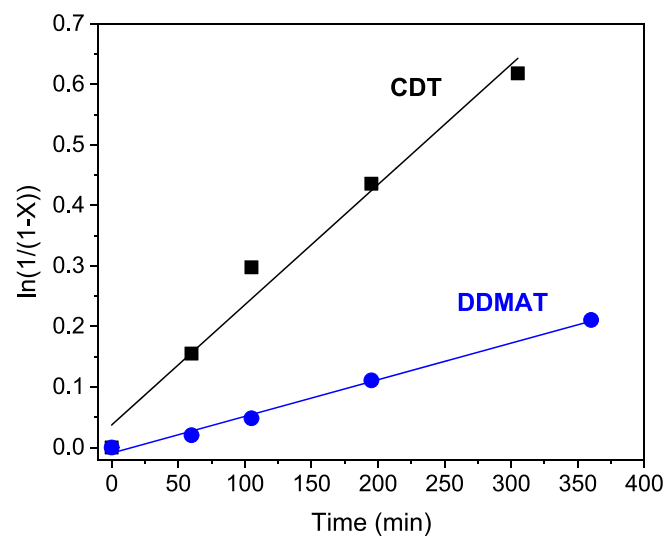

Figure 4. Semilogarithmic plot of the scaled conversion $[\ln (1-(1 /$ $\mathrm{X})$ )] , with $\mathrm{X}=$ monomer conversion of the homopolymerization of 4CPA with two RAFT agents: CDT (solid black square) and DDMAT (solid blue circle), Table 1 , entries 5 and 8 , respectively.

governs the rate of addition of propagating radicals, the difference lies in the RAFT pre-equilibrium and re-initiation stage. In this case, CDT with the cyanoalkyl R-group appears to be a more efficient chain transfer agent in contrast to DDMAT. ${ }^{65}$

${ }^{1} \mathrm{H}$ NMR and ${ }^{13} \mathrm{C}$ NMR spectroscopies were used to confirm the structure of poly(4CPA). In general, the proposed structure corresponds well with the spectra. The characteristic main chain $\left(-\mathrm{CH}_{2}-\mathrm{CH}-\right)$ signals at $1.5-2.5 \mathrm{ppm}$ are clearly observed in the ${ }^{1} \mathrm{H}$ NMR spectrum (Figure 5a). Based on the resonances at 6.36 and $7.60 \mathrm{ppm}$, which possess the same integral as the $(-\mathrm{O}-$ $\mathrm{CH}-$ ) protons in the cyclopentenone group, the internal double bond remains nearly intact during the polymerization, at least within the error margin of the NMR measurement. The doublebond content of the polymer (Table 1 , entry 3 ) was calculated in
${ }^{1} \mathrm{H}$ NMR by comparing the resonances at 6.36 and $7.60 \mathrm{ppm}$, with the main chain resonances between 1.40 and $2.12 \mathrm{ppm}$. At a conversion of $45.2,94 \%$ of the secondary double bonds were maintained in the polymer. The RAFT agent end group could also be observed, with the resonances of the methylene groups of the dodecyl chain at 1.27 and $3.38 \mathrm{ppm}$ and the methyl group at $0.89 \mathrm{ppm}$. The presence of the trithiocarbonate end group in the purified polymer indicates that RAFT conditions are maintained during the polymerizations. Also, in the ${ }^{13} \mathrm{C}$ NMR spectrum (Figure $5 \mathrm{~b}$ ) of poly (4CPA), the resonances corresponding to the internal double bond in the ring are present at 137.6 and $158.4 \mathrm{ppm}$. The peaks corresponding to the $(\mathrm{CH})$ group in the main chain and the methylene carbon of the pendent cyclopentenone group overlap at $40.84 \mathrm{ppm}$. However, DEPT analysis revealed the presence of both the secondary and tertiary substituted carbons (Figures S11 and S12).

3.3. Copolymerization of 4CPA. To reduce secondary reactions of the pendent cyclopentenone units in the RAFT polymerization of 4CPA and increase acrylate monomer conversion, copolymerization with several biobased comonomers was investigated. The comonomers that were used are isobornyl acrylate (IBA), methyl acrylate (MA), and lauryl acrylate (LA). Copolymerization was performed with a $40 \mathrm{wt} \%$ monomer concentration in DMF at $70{ }^{\circ} \mathrm{C}$ with $[\mathrm{AIBN}]_{0} /$ $[\mathrm{CDT}]_{0} /\left[\mathrm{M}_{1}\right]_{0} /\left[\mathrm{M}_{2}\right]_{0}=1 / 5 / 250 / 250$. The results are summarized in Table 2.

None of the copolymerizations resulted in insoluble networks, even at high conversions, which is an improvement compared to the homopolymerizations. Using $\mathrm{MA}$ as the comonomer and $[4 \mathrm{CPA}]_{0} /[\mathrm{MA}]_{0}=1 / 9$, the conversion of $4 \mathrm{CPA}$ reached $95 \%$ while maintaining a narrow dispersity of 1.19 (entry P2-1/9, Table 2). When the 4CPA-to-MA feed ratio was increased, the control over the molecular weight was lost due to the

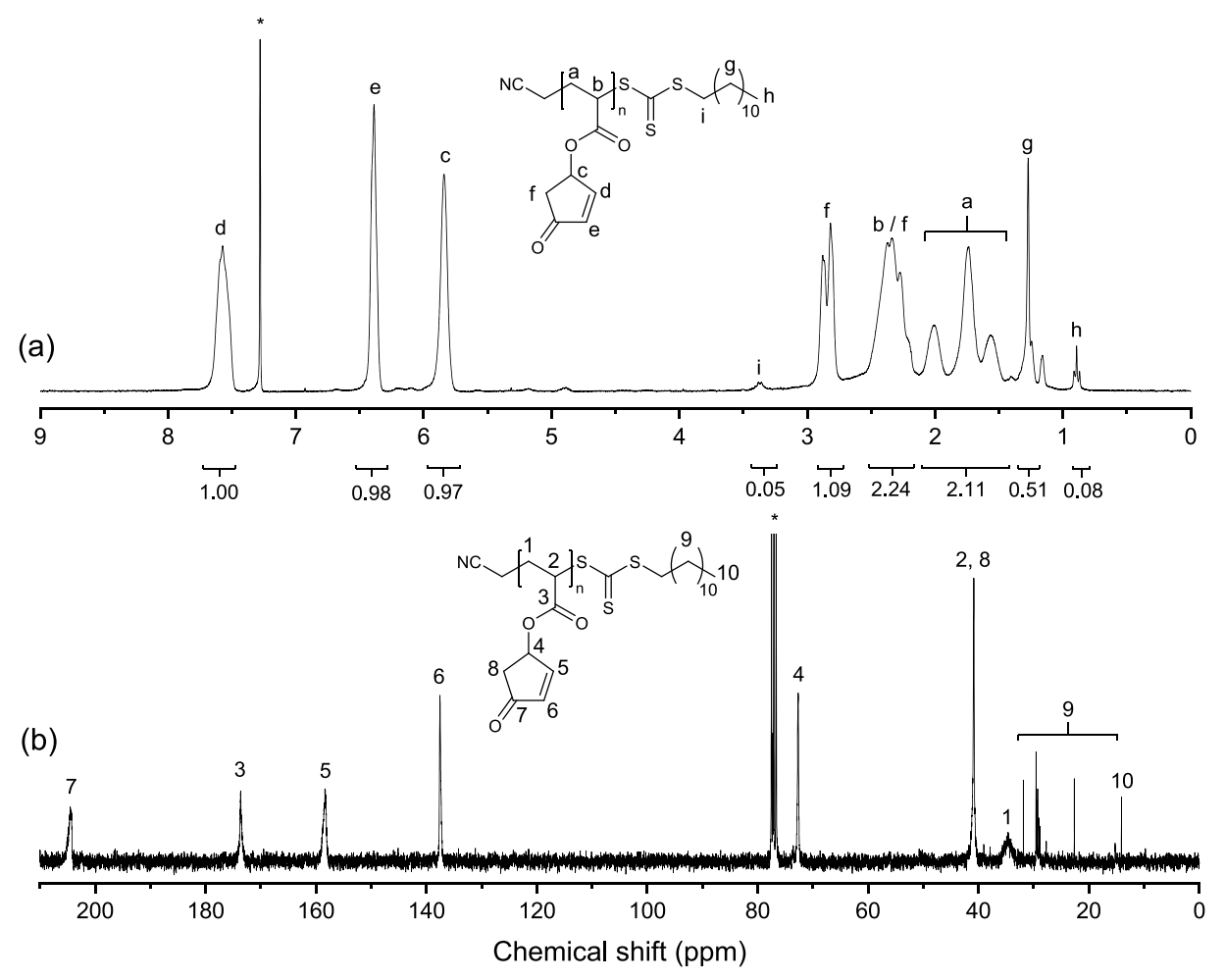

Figure 5. (a) ${ }^{1} \mathrm{H}$ NMR and (b) ${ }^{13} \mathrm{C}$ NMR spectra of poly(4CPA) (Table 1, entry 3) synthesized by RAFT polymerization using CDT as the RAFT agent. 

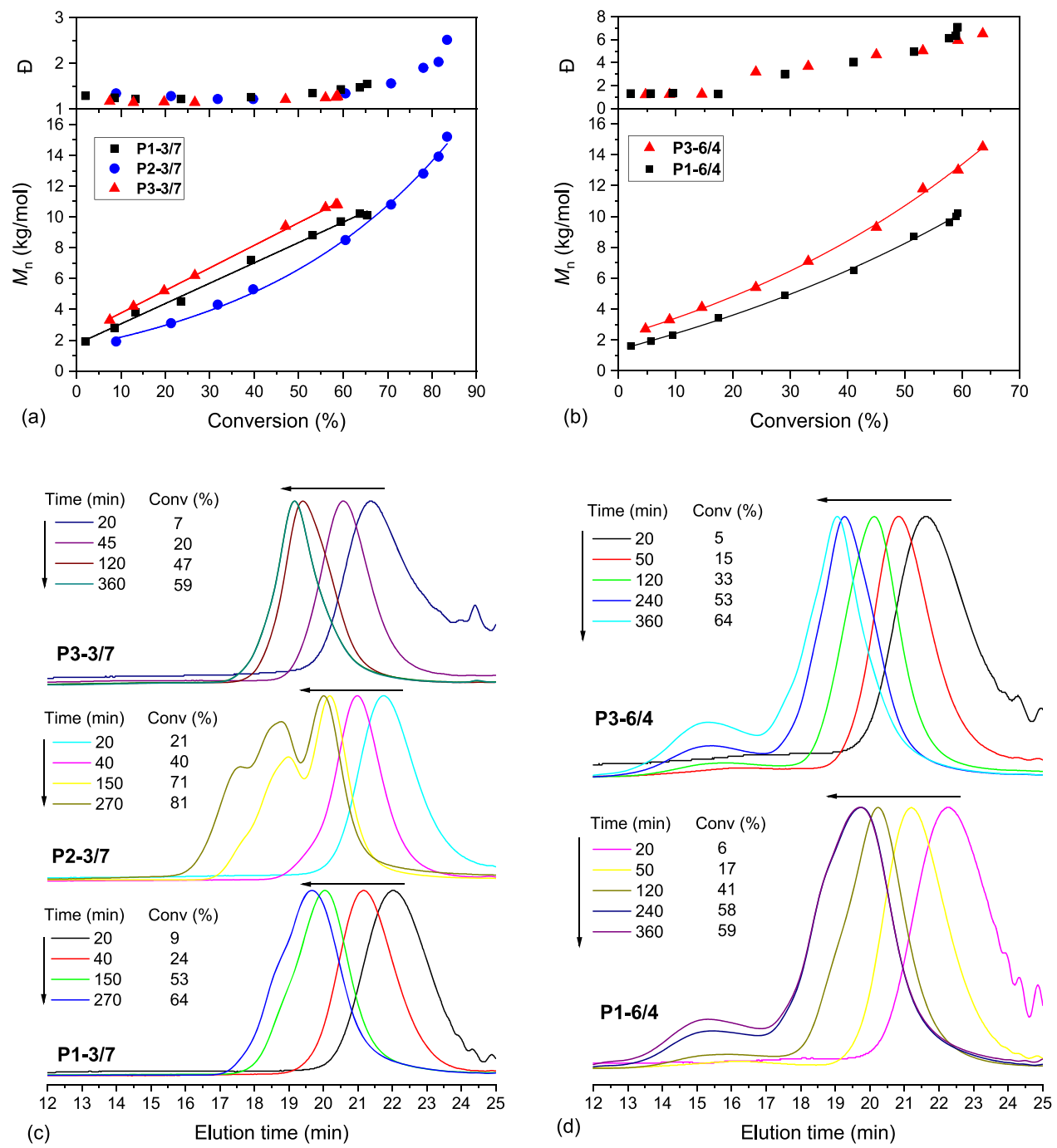

Figure 6. Molecular weight evolution over the total monomer conversion of the copolymers (a) P1-3/7, P2-3/7, and P3-3/7; (b) P3-6/4, P1-6/4, and (c) and (d) are the GPC traces over time of the same reactions. P1 = poly(4CPA-co-IBA), P2 = poly(4CPA-co-MA), and P3 = poly (4CPA-co- LA).

participation of the pendent cyclopentenone units, which in turn leads to branching and increase in the dispersity. At $[4 \mathrm{CPA}]_{0} /$ $[\mathrm{MA}]_{0}=3 / 7$, a sudden increase in molecular weight and dispersity occurred at $60 \%$ monomer conversion (Figure $6 \mathrm{a}$ ). The nonlinearity of the molecular weight with the conversion indicates that controlled conditions are not upheld during the polymerization. This is also represented in the GPC traces over time, which show the evolution of additional distributions in a later stage of the polymerization (Figure 6c). These do not appear as evidently for the copolymerizations with LA and IBA, though a slight increase in dispersity occurs. Also, higher DPs were reached with $\mathrm{MA}$, which contribute to the generally higher dispersity for poly(4CPA-co-MA). In the case of IBA and LA, a higher 4CPA incorporation was allowed without the loss of molecular weight control. Only when $[4 \mathrm{CPA}]_{0} /[\mathrm{LA}]_{0}$ and $[4 \mathrm{CPA}]_{0} /[\mathrm{IBA}]_{0}=6 / 4$, the molecular weight did not increase linearly with monomer conversion and high dispersities of the final copolymers were observed (Figure 6b). The evolution of a second distribution in the GPC traces indicates the onset of cross-linking reactions (Figure $6 \mathrm{~d}$ ). The steric hindrance of borneol and dodecanol esters of IBA and LA, respectively, are believed to reduce participation of the pendent cyclopentenone units in the polymerization as opposed to the less bulky MA.
In all copolymerizations, 4CPA was the fastest reacting monomer relative to MA, IBA, or LA (Figure $7 \mathrm{~b}-\mathrm{d}$ ). However, when the 4CPA feed fraction was lowered, a higher overall monomer reactivity was obtained. The initial monomer reactivity is shown in the semilogarithmic kinetic plot obtained for the copolymerization of 4CPA with MA (Figure 7a). The change in the steepness of the curve upon increasing the comonomer content was observed for all of the comonomers tested. This is another indication that chain termination and transfer events are more prevalent in the presence of 4CPA but do not affect the rate of $4 \mathrm{CPA}$ consumption relative to the comonomer.

The thermal behavior of the synthesized copolymers was analyzed by DSC to monitor the effect of the amount of the comonomer on the glass transition temperature. The homopolymer of 4CPA has a glass transition temperature of $62{ }^{\circ} \mathrm{C}$ (Figure $\mathrm{S} 13$ ), which is reduced to $55^{\circ} \mathrm{C}$ upon copolymerization with one monomer equivalent MA (Figure S14). Further incorporation of MA in the copolymer resulted in a significant decrease in the glass transition temperature from $55^{\circ} \mathrm{C}$ at $54 \%$ $\mathrm{MA}$ to $17{ }^{\circ} \mathrm{C}$ at $91 \% \mathrm{MA}$ incorporation. Alternatively, when 4CPA was copolymerized with IBA, a gradual increase in the glass transition temperature was observed for samples 

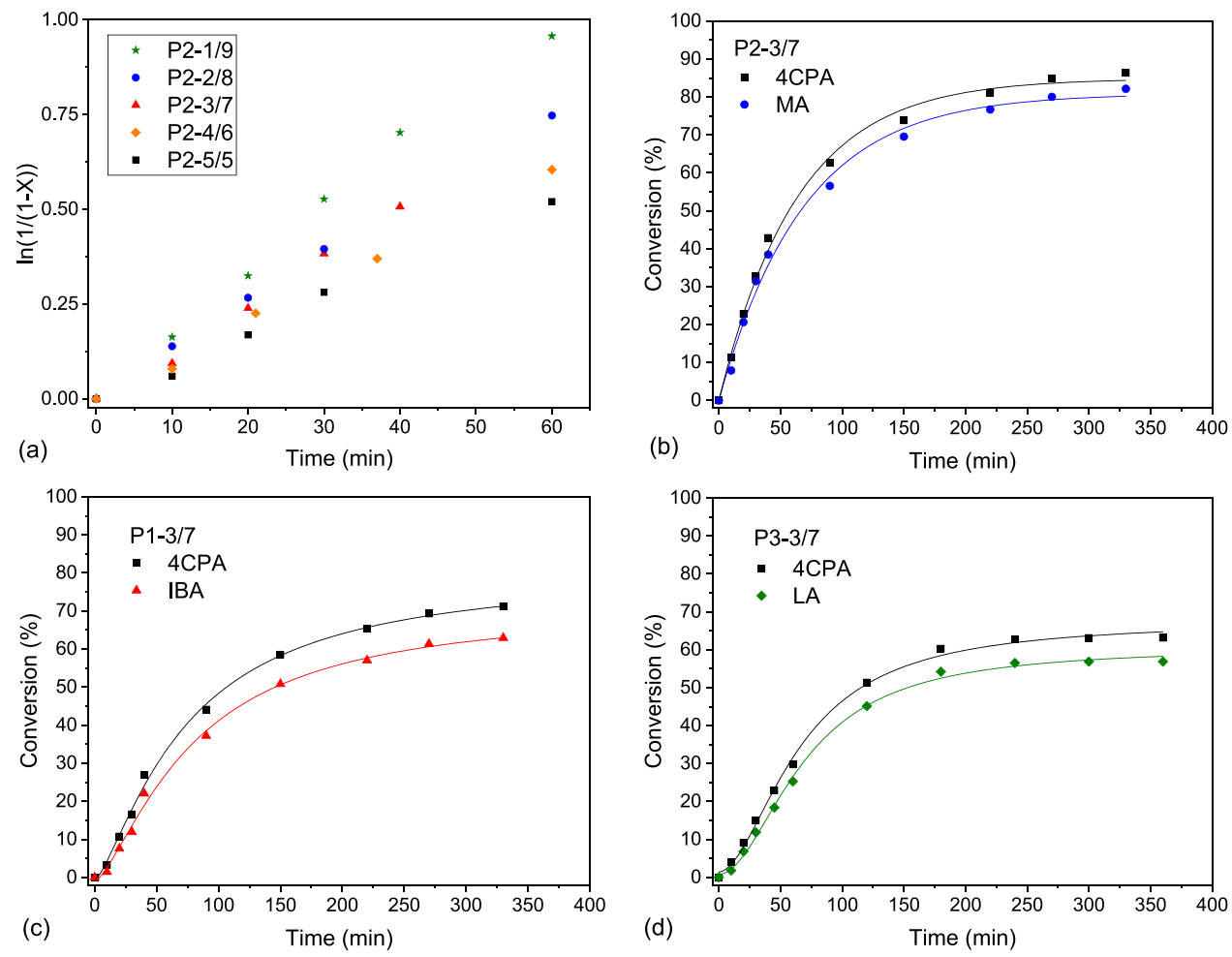

Figure 7. (a) First-order kinetic plots of the copolymerization of 4CPA with MA with different feed fractions of 4CPA, calculated from the overall conversion; conversion plots of the copolymerization of 4CPA with feed fraction 0.3 together with (b) MA, (c) IBA, and (d) LA.

containing a higher fraction of the rigid IBA. Poly 4 CPA-coIBA) containing $51 \%$ IBA had a $T_{\mathrm{g}}$ of $80{ }^{\circ} \mathrm{C}$, whereas $91 \%$ IBA incorporation resulted in a $T_{\mathrm{g}}$ of $96{ }^{\circ} \mathrm{C}$. Similar to copolymerization with MA, LA also had a reducing effect on the $T_{\mathrm{g}}$. Side chain crystallinity was observed for poly(4CPA-coLA) with LA fractions of 0.71 and 0.81 ; the latter has a melting point of $-3{ }^{\circ} \mathrm{C}$. The crystallinity of homopolymers ${ }^{66}$ and copolymers ${ }^{67}$ from (meth)acrylates containing long pendent $\mathrm{n}$ alkyl chains is known for these types of polymers.

In general, the $T_{\mathrm{g}}$ of a polymer is a physical process for amorphous polymers, affecting chain mobility, which is important for film formation and postpolymerization reactions. In this case, UV curing by the reaction of the pendent cyclopentenone units is the targeted cross-linking reaction. At temperatures above the $T_{\mathrm{g}}$, the increased mobility of the polymer chains favors the cross-linking reactions, resulting in a higher cross-linking degree. ${ }^{27}$ Furthermore, steric hindrance from bulky comonomers can influence the reactivity of side groups as well. ${ }^{68}$ Therefore, careful selection of the copolymer composition is required to achieve facile cross-linking.

In Figure 8, an overlay of the ${ }^{1} \mathrm{H}$ NMR spectra of the copolymers P1-3/7, P2-3/7, and P3-3/7 (Table 2) is shown. The peak signals correspond well with the proposed structures. ${ }^{1} \mathrm{H}$ NMR was also used to calculate the monomer ratio in the copolymer. This was performed by comparing the resonances of the $(\mathrm{H}-\mathrm{C}-\mathrm{O})$ protons of the monomers, which appear at 3.67, $4.02,4.64$, and $5.84 \mathrm{ppm}$ for MA, LA, IBA, and 4CPA, respectively. In general, the comonomer ratios in the final copolymer corresponded well with the monomer feed ratios even at incomplete conversion (Table 2). Unfortunately, the presence of the RAFT agent end group could only be assigned to copolymers containing MA, since the resonances originating from the methyl groups of LA and IBA overlap with those from the RAFT end group.

\section{PHOTODIMERIZATION OF (1)}

In the literature, the photodimerization of cyclopentenone is well established, ${ }^{69-72}$ but apart from one study in 1978, ${ }^{25}$ nothing was reported for 4-hydroxycyclopentenone. To demonstrate the photodimerization of 4CPA and polymers derived thereof in a model reaction, compound (1) was irradiated with UV light in acetone. This yielded a mixture of the two possible adducts, head-to-tail (HT) and head-to-head $(\mathrm{HH})$ (Scheme 2). The ratio between adducts $\mathrm{HT}$ and $\mathrm{HH}$ was found to be 53:47 by comparing the resonances corresponding to the $\mathrm{CH}-\mathrm{O}$ protons, which appear at 5.32 and $5.43 \mathrm{ppm}$ in the ${ }^{1} \mathrm{H}$ NMR spectrum (Figure 10a). In studies toward the photocyclodimerization of cyclopentenone, it was shown that the concentration and solvent polarity have a moderate influence on the $\mathrm{HT}$ and $\mathrm{HH}$ ratio, with $\mathrm{HH}$ adducts becoming more important at higher concentrations and in more polar solvents. ${ }^{70}$ Further characterization of the obtained dimers using direct injection MS confirmed the observations made in NMR, and a mass of $280 \mathrm{~g} / \mathrm{mol}$ was found, which corresponds to the dimer mass (Figure S15). Additional fragmentation masses of 220 and $160 \mathrm{~g} / \mathrm{mol}$ were observed, which belong to the elimination products (one or two molecules of acetic acid removed). In addition to experimental analysis, the different conformers were modeled using quantum mechanical simulations to obtain a clear picture of their contribution in the NMR spectrum.

4.1. Computational Modeling. 4.1.1. Temperature-Dependent Stability and Charge Distribution. The formation energy of the different conformers is calculated as

$$
E_{\mathrm{f}}=E_{\mathrm{di}}-2 E_{\text {mono }}
$$

with $E_{\mathrm{di}}$ and $E_{\text {mono }}$ the total energy for the dimer and monomer, respectively. In contrast to DFT calculations, experiments are 


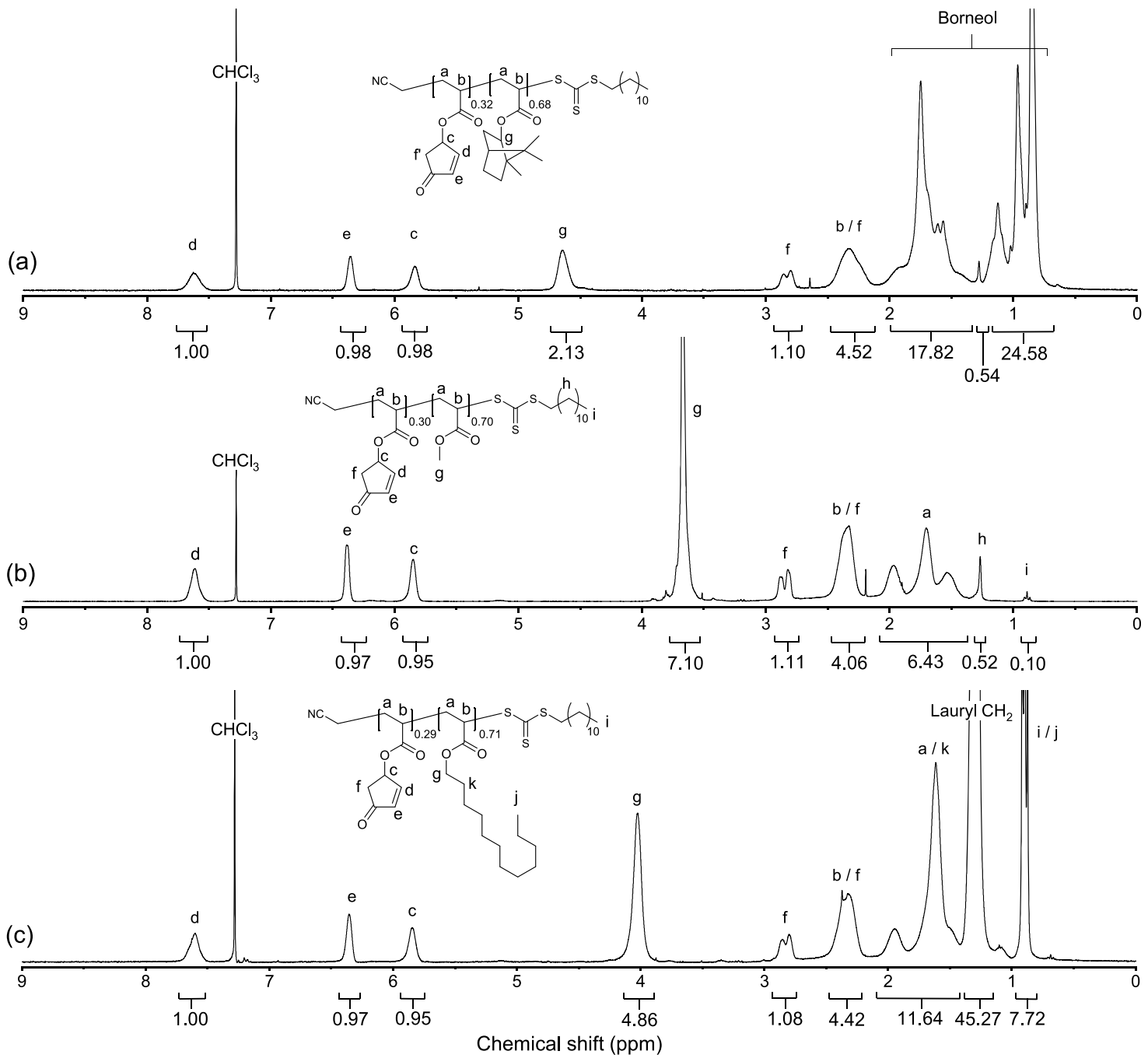

Figure 8. ${ }^{1} \mathrm{H}$ NMR spectra of copolymers (a) poly(4CPA-co-IBA) P1-3/7, (b) poly(4CPA-co-MA) P2-3/7, and (c) poly (4CPA-co-LA) P3-3/7 (300 $\left.\mathrm{MHz}, \mathrm{CDCl}_{3}\right)$.

Scheme 2. Photocyclodimerization of $(1)$ in Acetone Yielding the Head-to-Tail (HT) and Head-to-Head (HH) Dimers

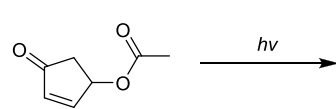

(1)

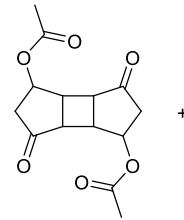

HT

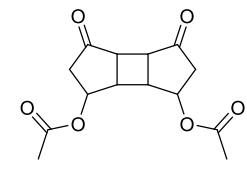

$\mathrm{HH}$ performed at finite temperatures. Using the vibrational spectrum of the conformers, the thermal energy contribution is estimated, providing the Gibbs free energy of formation for the dimers as $^{52,53}$

$$
\begin{aligned}
& \Delta G(p=0, T)=G_{\mathrm{di}}-2 G_{\mathrm{mono}}=\left(E_{\mathrm{di}}+E_{\mathrm{vib}, \mathrm{di}}-T S_{\mathrm{di}}\right) \\
& -2\left(E_{\mathrm{di}}+E_{\mathrm{vib}, \mathrm{mono}}-T S_{\mathrm{mono}}\right)
\end{aligned}
$$

with $E_{\mathrm{vib}, x}$ the vibrational internal energy and $S_{x}$ the vibrational entropy of the dimer and monomer. During photodimerization in the UV chamber, the solution reaches a maximum temperature of approximately $40^{\circ} \mathrm{C}$. The Gibbs free energy of formation at $40^{\circ} \mathrm{C}$ is given in Table 3 . As can be seen in Table 3 , the relative stability obtained at $0 \mathrm{~K}$ is retained even at experimentally relevant temperatures. A clear difference in

Table 3. Properties of the Conformers: Distance between Acetate Groups $\left(\Delta r_{\mathrm{AB}}\right)$; Atomic Charge on the Functional Groups: Acetate $\left(Q_{\mathrm{ace}}\right)$ and Methyl $\left(Q_{\text {meth }}\right)$; Formation Energy $\left(E_{\mathrm{f}}\right)$; Zero-Point Energy $(\mathrm{ZPE})$; Gibbs Free Energy $(\Delta G)$; and Distribution $\left(n_{\mathrm{A}}\right)$

$\begin{array}{lccccccc} & \Delta r_{\mathrm{AB}}(\AA) & Q_{\text {ace }}(\mathrm{e}) & Q_{\mathrm{meth}}(\mathrm{e}) & E_{\mathrm{f}}(\mathrm{meV}) & \mathrm{ZPE}(\mathrm{eV}) & \Delta G(p=0, T=313 \mathrm{~K})(\mathrm{meV}) & n_{\mathrm{A}}(T=313 \mathrm{~K})(\%) \\ \mathrm{HHb} & 7.519 & -0.18 & -0.11 & -40 & 7.492 & -16 & 0.00 \\ \mathrm{HTb} & 10.333 & -0.16 & -0.14 & -397 & 7.498 & -356 & 0.01 \\ \mathrm{HHc} & 10.455 & -0.17 & -0.10 & -619 & 7.499 & -590 & 83.58 \\ \mathrm{HTc} & 10.885 & -0.16 & -0.14 & -541 & 7.497 & -546 & 16.40\end{array}$


Table 4. Calculated Chemical Shift $\delta$ (ppm), Sorted Smallest to Largest

\begin{tabular}{|c|c|c|c|c|c|c|c|}
\hline \multicolumn{8}{|c|}{ chemical shift ${ }^{13} \mathrm{C}$} \\
\hline \multicolumn{2}{|c|}{$\mathrm{HHc}$} & \multicolumn{2}{|c|}{ HTc } & \multicolumn{2}{|c|}{$\mathrm{HHb}$} & \multicolumn{2}{|c|}{$\mathrm{HTb}$} \\
\hline$\delta$ & site & $\delta$ & site & $\delta$ & site & $\delta$ & site \\
\hline-160.47 & $\mathrm{C}_{\mathrm{H} 3} \mathrm{~A}$ & -160.85 & $\mathrm{C}_{\mathrm{H} 3} \mathrm{~A}$ & -161.75 & $\mathrm{C}_{\mathrm{H} 3} \mathrm{~B}$ & -160.97 & $\mathrm{C}_{\mathrm{H} 3} \mathrm{~A}$ \\
\hline-160.46 & $\mathrm{C}_{\mathrm{H} 3} \mathrm{~B}$ & -160.82 & $\mathrm{C}_{\mathrm{H} 3} \mathrm{~B}$ & -160.66 & $\mathrm{C}_{\mathrm{H} 3} \mathrm{~A}$ & -160.97 & $\mathrm{C}_{\mathrm{H} 3} \mathrm{~B}$ \\
\hline-134.20 & $\mathrm{C}_{\mathrm{H} 2} \mathrm{~A}$ & -135.56 & $\mathrm{C}_{\mathrm{H} 2} \mathrm{~B}$ & -130.40 & $\mathrm{C}_{\mathrm{CB}, *} \mathrm{~B}$ & -131.89 & $\mathrm{C}_{\mathrm{CB}, *} \mathrm{~A}$ \\
\hline-134.14 & $\mathrm{C}_{\mathrm{H} 2} \mathrm{~B}$ & -130.34 & $\mathrm{C}_{\mathrm{CB}, *} \mathrm{~B}$ & -130.09 & $\mathrm{C}_{\mathrm{CB}, *} \mathrm{~A}$ & -131.87 & $\mathrm{C}_{\mathrm{CB}, *} \mathrm{~B}$ \\
\hline-132.83 & $\mathrm{C}_{\mathrm{CB}, *} \mathrm{~A}$ & -130.10 & $\mathrm{C}_{\mathrm{CB}} \mathrm{A}$ & -129.85 & $\mathrm{C}_{\mathrm{H} 2} \mathrm{~B}$ & -128.78 & $\mathrm{C}_{\mathrm{CB}} \mathrm{A}$ \\
\hline-132.80 & $\mathrm{C}_{\mathrm{CB}, *} \mathrm{~B}$ & -130.04 & $\mathrm{C}_{\mathrm{H} 2} \mathrm{~A}$ & -129.81 & $\mathrm{C}_{\mathrm{H} 2} \mathrm{~A}$ & -128.78 & $\mathrm{C}_{\mathrm{CB}} \mathrm{B}$ \\
\hline-130.37 & $\mathrm{C}_{\mathrm{CB}} \mathrm{B}$ & -129.27 & $\mathrm{C}_{\mathrm{CB}, *} \mathrm{~A}$ & -126.24 & $\mathrm{C}_{\mathrm{CB}} \mathrm{B}$ & -127.87 & $\mathrm{C}_{\mathrm{H} 2} \mathrm{~A}$ \\
\hline-130.36 & $\mathrm{C}_{\mathrm{CB}} \mathrm{A}$ & -123.69 & $\mathrm{C}_{\mathrm{CB}} \mathrm{B}$ & -125.95 & $\mathrm{C}_{\mathrm{CB}} \mathrm{A}$ & -127.84 & $\mathrm{C}_{\mathrm{H} 2} \mathrm{~B}$ \\
\hline-96.86 & $\mathrm{C}_{\mathrm{H}-\mathrm{O}} \mathrm{A}$ & -102.11 & $\mathrm{C}_{\mathrm{H}-\mathrm{O}} \mathrm{B}$ & -101.55 & $\mathrm{C}_{\mathrm{H}-\mathrm{O}} \mathrm{A}$ & -99.65 & $\mathrm{C}_{\mathrm{H}-\mathrm{O}} \mathrm{A}$ \\
\hline-96.81 & $\mathrm{C}_{\mathrm{H}-\mathrm{O}} \mathrm{B}$ & -96.86 & $\mathrm{C}_{\mathrm{H}-\mathrm{O}} \mathrm{A}$ & -95.79 & $\mathrm{C}_{\mathrm{H}-\mathrm{O}} \mathrm{B}$ & -99.63 & $\mathrm{C}_{\mathrm{H}-\mathrm{O}} \mathrm{B}$ \\
\hline-2.02 & $\mathrm{C}_{\mathrm{O} 2} \mathrm{~A}$ & -1.63 & $\mathrm{C}_{\mathrm{O} 2} \mathrm{~B}$ & -6.25 & $\mathrm{C}_{\mathrm{O} 2} \mathrm{~B}$ & -1.82 & $\mathrm{C}_{\mathrm{O} 2} \mathrm{~B}$ \\
\hline-1.97 & $\mathrm{C}_{\mathrm{O} 2} \mathrm{~B}$ & -1.45 & $\mathrm{C}_{\mathrm{O} 2} \mathrm{~A}$ & -1.72 & $\mathrm{C}_{\mathrm{O} 2} \mathrm{~A}$ & -1.80 & $\mathrm{C}_{\mathrm{O} 2} \mathrm{~A}$ \\
\hline 46.20 & $\mathrm{C}_{\mathrm{O}} \mathrm{A}$ & 45.17 & $\mathrm{C}_{\mathrm{O}} \mathrm{A}$ & 41.36 & $\mathrm{C}_{\mathrm{O}} \mathrm{B}$ & 47.90 & $\mathrm{C}_{\mathrm{O}} \mathrm{A}$ \\
\hline 46.22 & $\mathrm{C}_{\mathrm{O}} \mathrm{B}$ & 45.75 & $\mathrm{C}_{\mathrm{O}} \mathrm{B}$ & 47.19 & $\mathrm{C}_{\mathrm{O}} \mathrm{A}$ & 47.97 & $\mathrm{C}_{\mathrm{O}} \mathrm{B}$ \\
\hline
\end{tabular}

${ }^{a_{T}}$ The atomic site indicated, as defined in Figure 9, with A and B used to distinguish between the monomers making up the dimer.

Table 5. Calculated Chemical Shift $\delta$ (ppm), Sorted Smallest to Largest ${ }^{a}$

\begin{tabular}{|c|c|c|c|c|c|c|c|}
\hline \multicolumn{8}{|c|}{ Chemical shift ${ }^{1} \mathrm{H}$} \\
\hline \multicolumn{2}{|c|}{$\mathrm{HHc}$} & \multicolumn{2}{|c|}{ HTc } & \multicolumn{2}{|c|}{$\mathrm{HHb}$} & \multicolumn{2}{|c|}{$\mathrm{HTb}$} \\
\hline$\delta$ & site & $\delta$ & site & $\delta$ & site & $\delta$ & site \\
\hline-29.108 & $\mathrm{H}_{3, *} \mathrm{~B}$ & -29.094 & $\mathrm{H}_{3, *} \mathrm{~B}$ & -29.031 & $\mathrm{H}_{3, *} \mathrm{~A}$ & -29.138 & $\mathrm{H}_{3, *} \mathrm{~B}$ \\
\hline-29.080 & $\mathrm{H}_{3, *} \mathrm{~A}$ & -29.013 & $\mathrm{H}_{3, *} \mathrm{~A}$ & -28.816 & $\mathrm{H}_{3, *} \mathrm{~B}$ & -29.137 & $\mathrm{H}_{3, *} \mathrm{~A}$ \\
\hline-28.820 & $\mathrm{H}_{3} \mathrm{~A}$ & -28.795 & $\mathrm{H}_{3} \mathrm{~B}$ & -28.809 & $\mathrm{H}_{3} \mathrm{~B}$ & -28.874 & $\mathrm{H}_{3} \mathrm{~A}$ \\
\hline-28.817 & $\mathrm{H}_{3} \mathrm{~A}$ & -28.779 & $\mathrm{H}_{3} \mathrm{~A}$ & -28.782 & $\mathrm{H}_{3} \mathrm{~A}$ & -28.874 & $\mathrm{H}_{3} \mathrm{~B}$ \\
\hline-28.815 & $\mathrm{H}_{3} \mathrm{~B}$ & -28.741 & $\mathrm{H}_{\mathrm{CB}, *} \mathrm{~B}$ & -28.736 & $\mathrm{H}_{3} \mathrm{~B}$ & -28.813 & $\mathrm{H}_{2, *} \mathrm{~B}$ \\
\hline-28.786 & $\mathrm{H}_{3} \mathrm{~B}$ & -28.708 & $\mathrm{H}_{3} \mathrm{~A}$ & -28.697 & $\mathrm{H}_{3} \mathrm{~A}$ & -28.811 & $\mathrm{H}_{2, *} \mathrm{~A}$ \\
\hline-28.531 & $\mathrm{H}_{2, *} \mathrm{~A}$ & -28.605 & $\mathrm{H}_{3} \mathrm{~B}$ & -28.595 & $\mathrm{H}_{2, *} \mathrm{~B}$ & -28.663 & $\mathrm{H}_{3} \mathrm{~A}$ \\
\hline-28.511 & $\mathrm{H}_{2, *} \mathrm{~B}$ & -28.593 & $\mathrm{H}_{2, *} \mathrm{~B}$ & -28.159 & $\mathrm{H}_{2} \mathrm{~B}$ & -28.663 & $\mathrm{H}_{3} \mathrm{~B}$ \\
\hline-28.412 & $\mathrm{H}_{\mathrm{CB}} \mathrm{B}$ & -28.276 & $\mathrm{H}_{2} \mathrm{~A}$ & -28.004 & $\mathrm{H}_{2} \mathrm{~A}$ & -27.792 & $\mathrm{H}_{2} \mathrm{~A}$ \\
\hline-28.412 & $\mathrm{H}_{\mathrm{CB}} \mathrm{A}$ & -28.061 & $\mathrm{H}_{2, *} \mathrm{~A}$ & -27.956 & $\mathrm{H}_{2, *} \mathrm{~A}$ & -27.785 & $\mathrm{H}_{2} \mathrm{~B}$ \\
\hline-28.026 & $\mathrm{H}_{\mathrm{CB}, *} \mathrm{~B}$ & -27.910 & $\mathrm{H}_{2} \mathrm{~B}$ & -27.742 & $\mathrm{H}_{\mathrm{CB}} \mathrm{B}$ & -27.680 & $\mathrm{H}_{\mathrm{CB}, *} \mathrm{~A}$ \\
\hline-28.020 & $\mathrm{H}_{\mathrm{CB}, *} \mathrm{~A}$ & -27.783 & $\mathrm{H}_{\mathrm{CB}, *} \mathrm{~B}$ & -27.738 & $\mathrm{H}_{\mathrm{CB}, *} \mathrm{~A}$ & -27.679 & $\mathrm{H}_{\mathrm{CB}, *} \mathrm{~B}$ \\
\hline-27.806 & $\mathrm{H}_{2} \mathrm{~A}$ & -27.578 & $\mathrm{H}_{\mathrm{CB}} \mathrm{B}$ & -27.711 & $\mathrm{H}_{\mathrm{CB}, *} \mathrm{~B}$ & -27.549 & $\mathrm{H}_{\mathrm{CB}} \mathrm{B}$ \\
\hline-27.801 & $\mathrm{H}_{2} \mathrm{~B}$ & -27.451 & $\mathrm{H}_{\mathrm{CB}} \mathrm{A}$ & -27.618 & $\mathrm{H}_{\mathrm{CB}} \mathrm{A}$ & -27.546 & $\mathrm{H}_{\mathrm{CB}} \mathrm{A}$ \\
\hline-25.424 & $\mathrm{H}_{\mathrm{br}} \mathrm{B}$ & -25.311 & $\mathrm{H}_{\mathrm{br}} \mathrm{B}$ & -25.817 & $\mathrm{H}_{\mathrm{br}} \mathrm{B}$ & -25.448 & $\mathrm{H}_{\mathrm{br}} \mathrm{B}$ \\
\hline-25.412 & $\mathrm{H}_{\mathrm{br}} \mathrm{A}$ & -25.075 & $\mathrm{H}_{\mathrm{br}} \mathrm{A}$ & -25.299 & $\mathrm{H}_{\mathrm{br}} \mathrm{A}$ & -25.446 & $\mathrm{H}_{\mathrm{br}} \mathrm{A}$ \\
\hline
\end{tabular}

${ }^{a_{a}}$ The atomic site indicated, as defined in Figure 9, with A and B used to distinguish between the monomers making up the dimer.

stability between the chair and boat conformers is present, with the former showing the highest stability. In contrast to the expectations, this difference is not solely due to steric interaction between the methyl groups, as can be seen from the distances between the carbons of the methyl groups $\left(\Delta r_{\mathrm{AB}}\right)$. Furthermore, the differences in the energy contribution due to dispersive Van der Waals interactions are limited to less than $70 \mathrm{meV}$, with the boat conformers being stabilized most. In addition, the charge on the acetate $\left(Q_{\text {ace }}\right)$ and specifically the methyl $\left(Q_{\text {meth }}\right)$ groups presents only minute variations between the different conformers, showing the conformers to have the same charge distribution and thus very similar Coulombic interactions between the acetate and methyl groups.

Although the four conformers give rise to the same zero-point energy (ZPE), the vibrational energy contribution is significantly different. Although the stability of the HHc conformer is decreased, that of the HTc conformer is slightly increased at 313 $\mathrm{K}$. Even more, at the PBE level, the HTc conformer is predicted to become more stable than the $\mathrm{HHc}$ conformer at $698 \mathrm{~K}$ (Figure S2). If we assume that the distribution of the different conformers is governed by Boltzmann statistics, then the relative distribution of a conformer $\mathrm{A}$ is given by

$$
n_{\mathrm{A}}=\frac{\mathrm{e}^{-\Delta G_{\mathrm{A}} / k_{\mathrm{B}} T}}{\sum_{\mathrm{B}} \mathrm{e}^{-\Delta G_{\mathrm{B}} / k_{\mathrm{B}} T}}
$$

At $40{ }^{\circ} \mathrm{C}$, PBE predicts about $16 \%$ of the dimers to be the HTc conformer and $84 \%$ the $\mathrm{HHc}$ conformer.

4.1.2. Simulated NMR. Chemical shifts were calculated for the four different conformers. The resulting shifts for $\mathrm{H}, \mathrm{C}$, and $\mathrm{O}$, including core contributions, are presented in Tables 4,5, and S2, respectively. ${ }^{73}$ Figure 9 shows the annotation of the different atomic sites. SI Section S2 furthermore contains more details about the methodology used to calculate the NMR shifts.

The chemical shifts for $\mathrm{C}$, presented in Table 4, can be separated in five distinct bands: (1) a narrow methyl band $\left(\mathrm{C}_{\mathrm{H} 3}\right)$ 


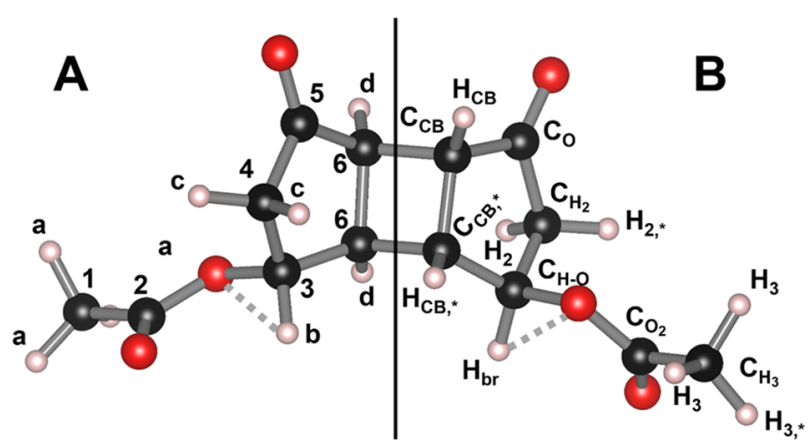

Figure 9. Ball-and-stick representation of a $\mathrm{HHc}$ dimer of (1). The atomic sites as associated with the experimentally observed spectrum are indicated on the A monomer. In the case of spectral lines resulting from a $\mathrm{HH}$ dimer, a prime is added to this notation. On the $\mathrm{B}$ monomer, the atomic sites giving rise to the simulated spectrum are indicated. The same notation is used for all four conformers. An additional annotation of $\mathrm{A} / \mathrm{B}$ is used to indicate the $\mathrm{A}$ or $\mathrm{B}$ monomer of the dimer, respectively.

at -161 to $-160 \mathrm{ppm},(2)$ a broad band ranging from -123 to $136 \mathrm{ppm}$ related to the carbons of the cyclobutane ring $\left(\mathrm{C}_{\mathrm{CB}}\right)$ and the two $\mathrm{CH}_{2}$ sites $\left(\mathrm{C}_{\mathrm{H} 2}\right)$, (3) a narrow band for the carbon near the hydrogen-bridged site $\left(\mathrm{C}_{\mathrm{H}-\mathrm{O}}\right)$ at about -96 to -102 ppm, (4) a narrow band for the carbon bound to the oxygen atoms in the acetate group $\left(\mathrm{C}_{\mathrm{O} 2}\right)$ at about $-2 \mathrm{ppm}$, and (5) a narrow band at around $46 \mathrm{ppm}$ due to the carbon with the double bond in the five rings of the conformers $\left(\mathrm{C}_{\mathrm{O}}\right)$.

Comparison with the experimental spectrum (Figure 10b) shows excellent qualitative agreement and allows for the matching of the experimentally observed peaks and the underlying structure. Focusing our attention on the chemical shifts of the $\mathrm{C}_{\mathrm{H} 3}, \mathrm{C}_{\mathrm{O} 2}$, and $\mathrm{C}_{\mathrm{O}}$, we note that the experimental peaks show small splittings of $0.13,0.20$, and $0.78 \mathrm{ppm}$, respectively. All conformers present a similar small splitting, with the sole exception being the HHb conformer, which was calculated to be the least stable conformer. The latter presents peak splittings of $1.09,4.53$, and $5.83 \mathrm{ppm}$ for the respective chemical shifts, making it highly unlikely to be a good model for the experimentally observed spectrum. The splitting of the $\mathrm{C}_{\mathrm{H}-\mathrm{O}}$ peak of $5.15 \mathrm{ppm}$ is present only for the HTc and the $\mathrm{HHb}$ conformers. With the HTc conformer being energetically the second most likely conformer, this experimentally observed splitting may be an indication of the presence of a mixture of the $\mathrm{HHc}$ and HTc conformers. In contrast to these narrow bands, the order of the peaks in the broad band is not clearly defined and changes significantly between conformers. Together with DEPT-135 experiments (Figure S16), which distinguishes the methylene protons from the cyclobutane protons between 38 and $48 \mathrm{ppm}$, and heteronuclear single quantum coherence (HSQC) (Figure S17), which shows coupling between $\mathrm{C}_{\mathrm{H}-\mathrm{O}}$
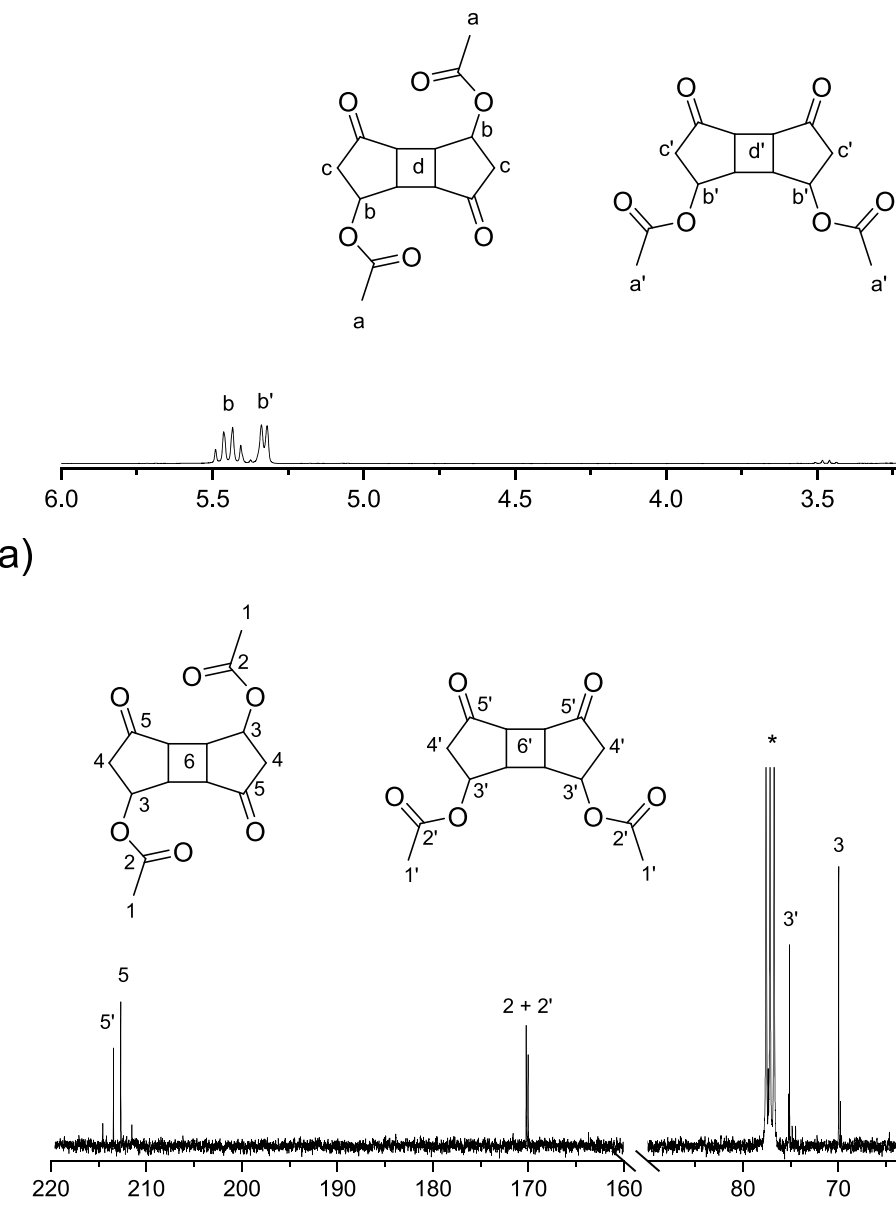

5.0

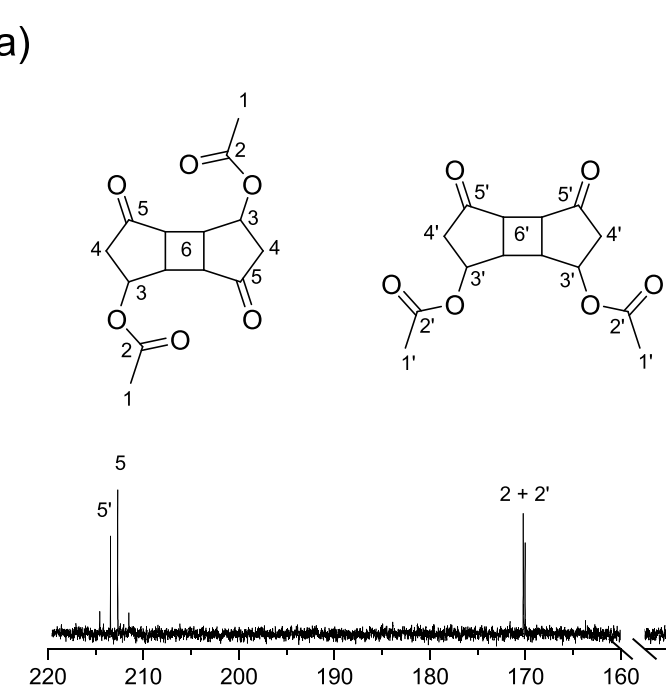

$4.0 \quad 3.5$

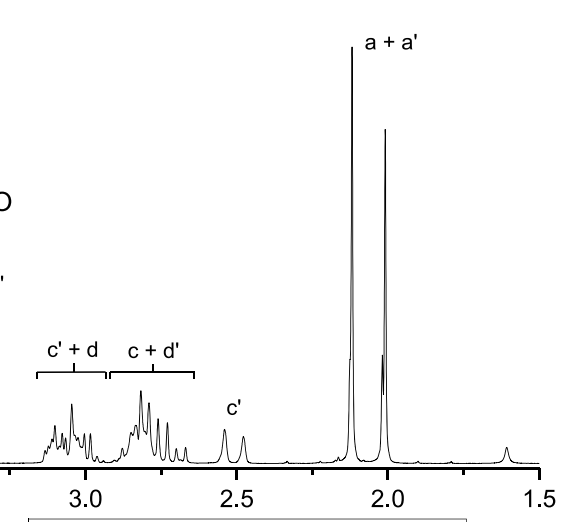

(a)

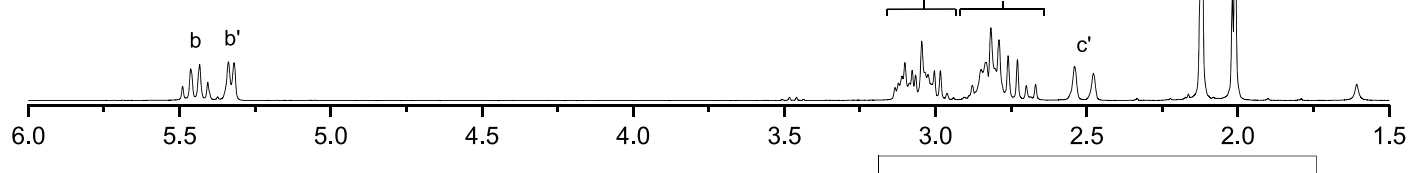

(b)

Chemical shift (ppm)

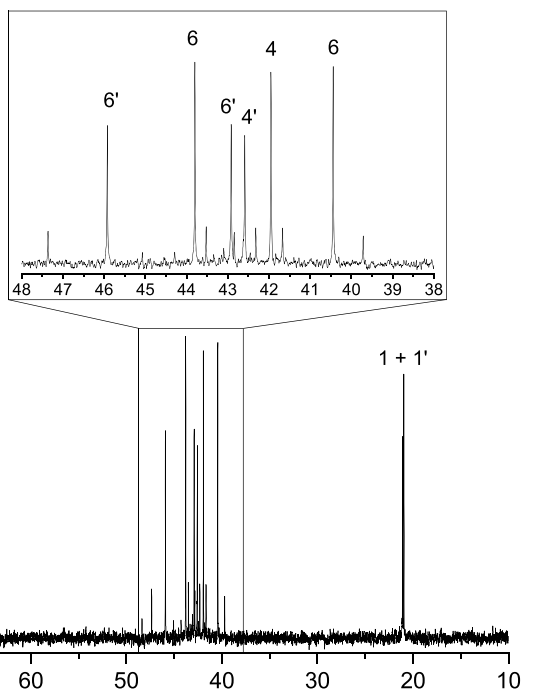

Figure 10. (a) ${ }^{1} \mathrm{H}$ NMR and (b) ${ }^{13} \mathrm{C}$ NMR of the $\mathrm{HT}$ and $\mathrm{HH}$ dimer of (1). 

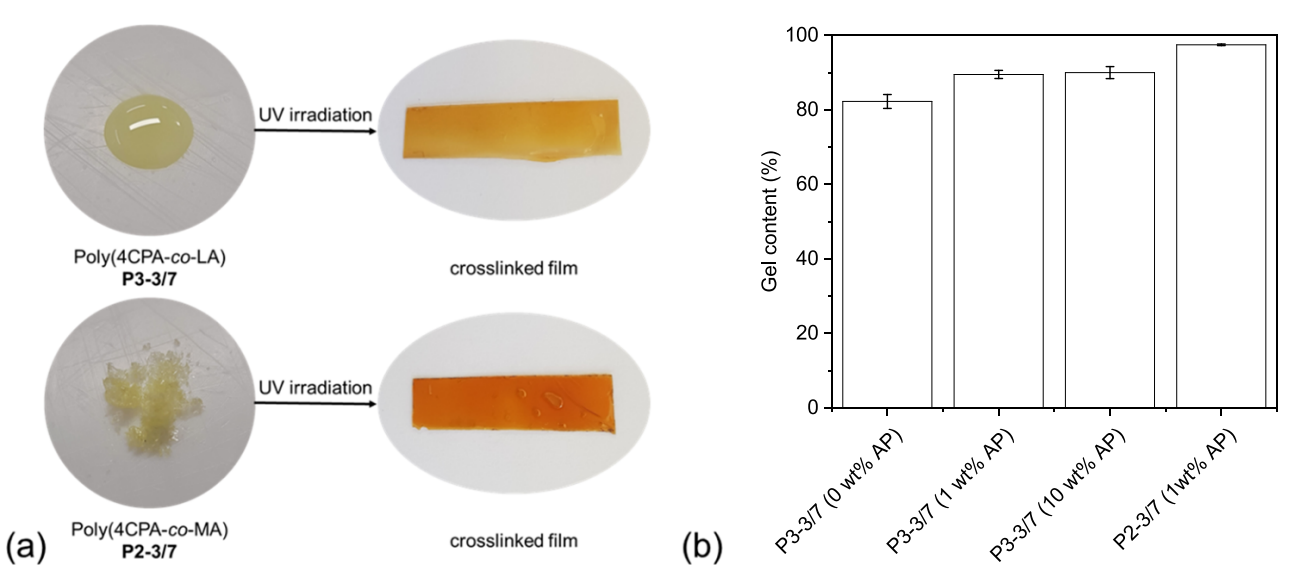

Figure 11. (a) Preparation of the UV cross-linked films of poly(4CPA-co-LA) and poly(4CPA-co-MA). (b) Gel content for the copolymer formulations in $\mathrm{CHCl}_{3}$ prepared with various amounts of $\mathrm{AP}$ as a photosensitizer. $\mathrm{P} 2=$ poly $(4 \mathrm{CPA}-c o-\mathrm{MA})$ and $\mathrm{P} 3=$ poly $(4 \mathrm{CPA}-c o-\mathrm{LA})$.

carbons and the attached protons, all of the spectral lines in the ${ }^{13} \mathrm{C}$ NMR spectrum could be assigned.

In the case of the $\mathrm{H}$ chemical shifts, there are three distinctive bands present: (1) an intense narrow band related to the methyl group $\left(\mathrm{H}_{3}\right)$ at -29.1 to $-28.8 \mathrm{ppm},(2)$ a broad band from about -27.5 to $28.8 \mathrm{ppm}$ related to the $\mathrm{H}$ on the cyclobutane ring $\left(\mathrm{H}_{\mathrm{CB}}\right)$ and $\mathrm{CH}_{2}$ site $\left(\mathrm{H}_{2}\right)$, and $(3)$ a narrow band between -26 and -25 ppm related to the $\mathrm{H}$ forming a hydrogen bridge $\left(\mathrm{H}_{\mathrm{br}}\right)$. This grouping shows good qualitative agreement with the experimental observations (Figure 10a).

The splitting of the intense methyl band gives rise to a rather interesting observation: the lower peak corresponds to $\mathrm{H}$ atoms having an eclipsed configuration with either of the oxygen atoms of the acetate group $\left(\mathrm{H}_{3, *}\right)$, while the higher peak corresponds to the other hydrogens $\left(\mathrm{H}_{3}\right)$. The splitting between the average chemical shifts is $0.29,0.33,0.17$, and $0.37 \mathrm{ppm}$ for the HHc, $\mathrm{HTc}, \mathrm{HHb}$, and $\mathrm{HTb}$ conformers, respectively. This shows good agreement with the experimental splitting of $0.11 \mathrm{ppm}$. At this point, it is important to note that the methyl group is expected to rotate freely at room temperature (Figure S1), thus allowing the methyl hydrogens to spontaneously switch between $\mathrm{H}_{3, *}$ and $\mathrm{H}_{3}$ configurations. If we assume the experimental spectrum to be mainly attributed to the $\mathrm{HHc}$ conformer, then the structure observed in the broad second band can be split into three subbands. Of these, the two outer bands originate from the $\mathrm{H}_{2}$, while the middle band originates from the $\mathrm{H}_{\mathrm{CB}}$. The experimental splitting of about $0.51 \mathrm{ppm}$ between the outer bands shows very good agreement with the splitting of $0.72 \mathrm{ppm}$ between the calculated chemical shifts of $\mathrm{H}_{2}$,* and $\mathrm{H}_{2}$ of the $\mathrm{HHc}$ conformer. In addition, the width of the middle band is for both the experimental $(\sim 0.25 \mathrm{ppm})$ and simulated $(\sim 0.39 \mathrm{ppm})$ cases roughly half this splitting, further corroborating this assignment. These results are supported by HSQC measurements (Figure S17), which show coupling with the cyclobutane and methylene carbons and therefore allow a more detailed assignment of the three multiplets between 2.4 and $3.2 \mathrm{ppm}$ in the ${ }^{1} \mathrm{H}$ NMR spectrum. Finally, the splitting of the $\mathrm{H}_{\mathrm{br}}$ peak in the experimental spectrum cannot be solely attributed to the $\mathrm{HHc}$ conformer. Of the other conformers, only the HTc conformer provides suitable $\mathrm{H}_{\mathrm{br}}$ spectral lines ( $\mathrm{HHb}$ shows a too large splitting of $0.5 \mathrm{ppm}$, while $\mathrm{HTb}$ provides a peak at almost the same position, differing merely $0.03 \mathrm{ppm}$ with the $\mathrm{HHc}$ peak). The $\mathrm{H}_{\mathrm{br}}$ lines are positioned 0.10 to $0.34 \mathrm{ppm}$ above that of the HHc conformer, explaining the observed broadening of this peak. It must be noted that some additional peak splitting in the experimental spectrum can be expected since the dimer mixture consists of not only conformers but also stereoisomers. Indeed, small signals are observed in the ${ }^{13} \mathrm{C}$ NMR spectrum close to the main signals, and additional (minor) splitting of the methyl groups in the ${ }^{1} \mathrm{H}$ NMR spectrum is also observed.

\section{PHOTO-CROSS-LINKING}

With these promising results, we continued with the photocross-linking of 4CPA copolymers to produce thin films (Figure 11a). Poly(4CPA-co-LA) P3-3/7 and poly(4CPA-co-MA) P2$3 / 7$ were prepared on a large scale for UV-curing experiments. Unfortunately, the cured film of polymer P1-3/7 turned out to be too brittle to produce freestanding thin films. The polymers were cured for $30 \mathrm{~min}$ on both sides in a UV chamber under a nitrogen flow. In the chamber, the temperature of the film reached a maximum of $90{ }^{\circ} \mathrm{C}$ after 60 min irradiation, which is well above the $T_{\mathrm{g}}$ of P2-3/7 and P3-3/7. Curing of thin polymer films proceeded without the addition of a photoinitiator or cross-linker. Therefore, since $\alpha, \beta$-unsaturated ketones have been shown to readily dimerize under UV light, cross-linking occurs via a photodimerization between the pendent cyclopentenone units. The addition of acetophenone (AP) as a photosensitizer improved the cross-linking slightly. Several weight ratios of copolymer and AP were investigated.

To test the degree of cross-linking of the produced films, swelling studies were performed; the obtained gel content values are summarized in Figure 11b. The films showed a high swell ratio in chloroform, which is a good solvent for the copolymers (Figure S18). In general, the films exhibited a high cross-linking degree. For poly(4CPA-co-LA) P3-3/7, the gel content ranged between 82 and $90 \%$ depending on the AP concentration. Upon the addition of 1 wt $\%$ of $\mathrm{AP}$, the gel content increased from 82 to $89.5 \%$. Increasing the AP concentration to $10 \mathrm{wt} \%$ did not result in a significant change in the gel content after $60 \mathrm{~min}$ curing. It was therefore decided to continue with the formulation containing 1 wt \% AP for further characterization. Polymer poly(4CPA-co-MA) P2-3/7 was only cross-linked using 1 wt $\%$ $\mathrm{AP}$, which resulted in a gel content of $97 \%$. The reason for the lower gel content in P3-3/7 compared to P2-3/7 could be the steric hindrance of the bulkier lauryl acrylate units, which reduce intermolecular reactions, and instead, intramolecular homolytical cleavage reactions are promoted. As a control, the homopolymer of lauryl acrylate was prepared according to the same procedure for the copolymerizations, except DMF was replaced by toluene as the solvent. Irradiation of a layer of the 
homopolymer for a total of $60 \mathrm{~min}$ did not result in any crosslinking. The polymer dissolved completely when it was introduced in chloroform. This confirms that the introduction of 4CPA in the polymer chain results in cross-linking under UV light.

FT-IR was used to characterize the change in functional groups as a result of the cross-linking (Figure 12). For both

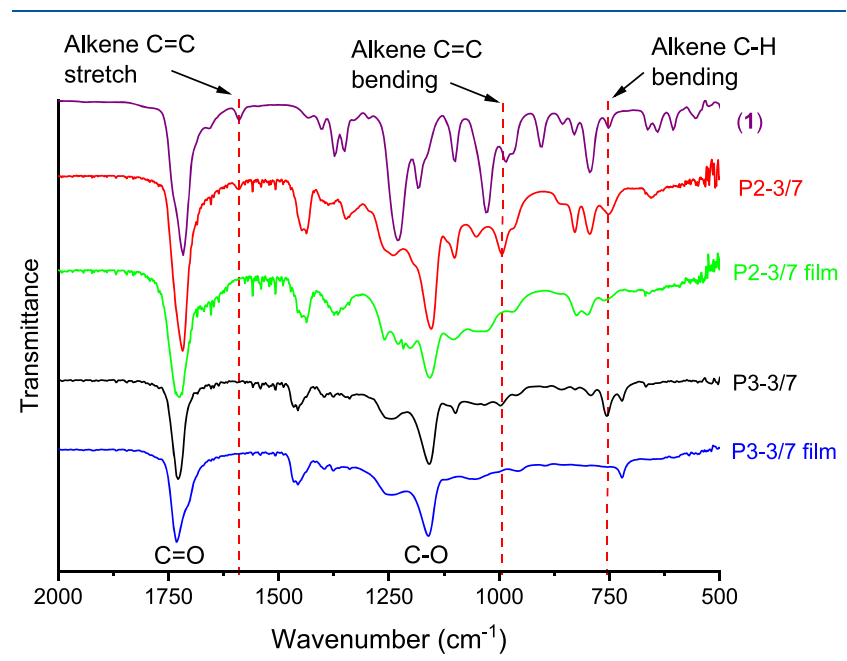

Figure 12. IR spectra of the 4CPA copolymers before and after crosslinking under UV light, in purple: (1), red: poly(4CPA-co-MA) P2-3/7, green: the cross-linked film of P2-3/7, black: poly(4CPA-co-LA) P3-3/ 7, and blue: the cross-linked film of P3-3/7.

poly(4CPA-co-MA) P2-3/7 and poly(4CPA-co-LA) P3-3/7, characteristic bands corresponding to the internal double bond in the ring disappeared. The $\mathrm{C}-\mathrm{H}$ bending at $756 \mathrm{~cm}^{-1}$ and the $\mathrm{C}=\mathrm{C}$ bending at $994 \mathrm{~cm}^{-1}$ of the carbon-carbon double-bond peak disappeared after UV light irradiation of $60 \mathrm{~min}$. Unfortunately, the change in the $\mathrm{C}=\mathrm{C}$ stretch absorption peak at $1590 \mathrm{~cm}^{-1}$ is observed only in the MA copolymer, where it appears as a very weak signal.

The cross-linked films were characterized by DMA and DSC to observe the changes in physical properties as a result of photocross-linking. The DSC of the cross-linked film of poly(4CPAco-MA) P2-3/7 clearly showed an increase in $T_{\mathrm{g}}$ of about $18{ }^{\circ} \mathrm{C}$ compared to the non-cross-linked polymer (Figure 13a). The observed $T_{\mathrm{g}}$ of $47^{\circ} \mathrm{C}$ corresponds well with what is observed in DMA, where the intersection of the tangents of the storage modulus lies at $45{ }^{\circ} \mathrm{C}$ (Figure 14a). A broad transition is observed in the DMA spectrum, as indicated by the storage and loss moduli, which may be explained by incomplete cross-linking or dangling chain ends. In the case of the LA copolymer P3-3/7, two endothermic events overlap in both the polymer and the cross-linked film. In the DSC traces (Figure 13b), a melting peak is observed between -30 and $10{ }^{\circ} \mathrm{C}$, which arises from the side chain crystallinity. As mentioned before, this occurs only in copolymers containing a high LA fraction. Modulated DSC experiments with fast cooling rates did not result in the disappearance of the melting peak. The melt peak is superimposed on a glass transition, indicated by the difference in baseline levels before and after the transition. A similar event is observed in DMA, where a large decrease at approximately $0{ }^{\circ} \mathrm{C}$ (Figure 14b) follows a small decrease in the loss modulus at approximately $-30^{\circ} \mathrm{C}$. The intersection of the tangents of the storage modulus lies at $-3{ }^{\circ} \mathrm{C}$, which corresponds to the melting temperature of the side chain crystals formed in homo- and copolymers of LA. Therefore, it is suspected that the first transition corresponds to the glass transition and the second to the melting of the side chain crystals.

\section{CONCLUSIONS}

In this work, the polymerization of a novel biobased acrylate monomer, which contains a cyclopentenone group, is presented. The pendent units can undergo $[2+2]$ photocyclodimerization to produce cross-linked networks. We have demonstrated the controlled (co)polymerization of 4CPA via the acrylate without gel formation via the cyclopentenone unit, resulting in polymers with narrow dispersity. To obtain polymers with a higher targeted DP (e.g., 100), copolymerization with a comonomer under RAFT conditions is required. The type and amount of the comonomer did affect the control during polymerization. Comonomers with a large side group provide more steric hindrance around the pendent double bonds in the ring and thus allow a larger incorporation of 4CPA while maintaining control over the molecular weight.

With the help of model studies, dimerization via $[2+2]$ photocycloaddition was demonstrated for the model compound 4-oxocyclopent-2-en-1-yl acetate. First-principles quantum mechanical simulations were used to identify the experimentally
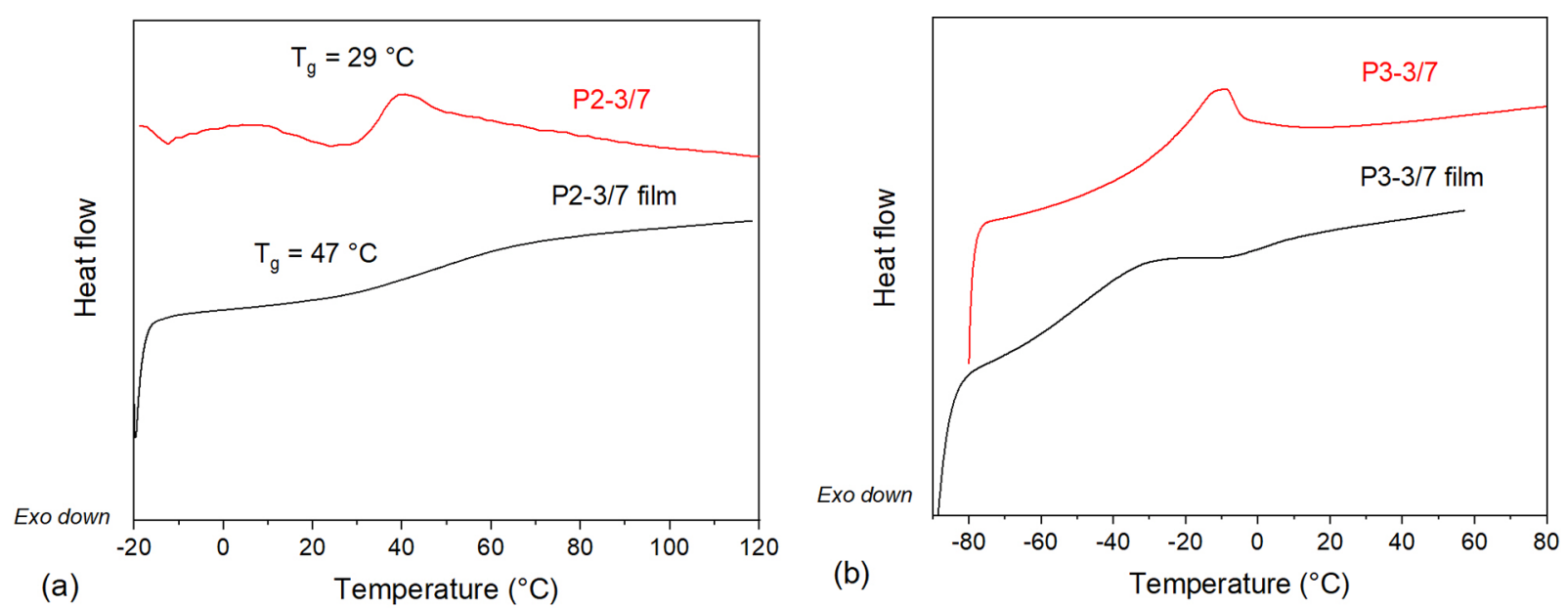

Figure 13. DSC traces of the polymers (red) and cross-linked films (black) of (a) poly(4CPA-co-MA) P2-3/7 and (b) poly(4CPA-co-LA) P3-3/7. 

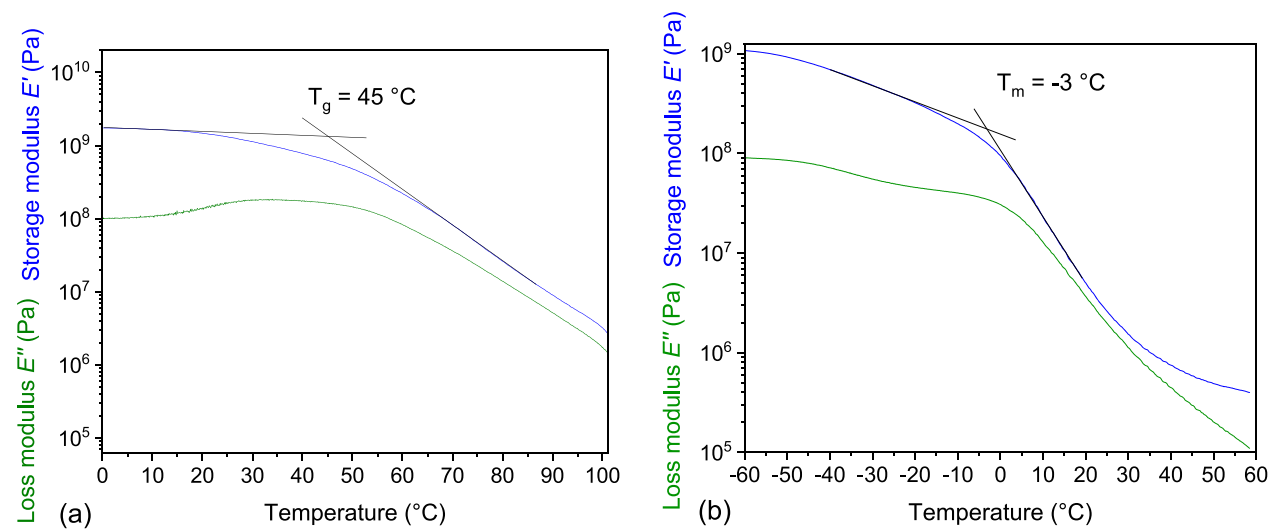

Figure 14. DMA traces of the cross-linked films of (a) poly(4CPA-co-MA) P2-3/7 and (b) poly(4CPA-co-LA) P3-3/7.

observed conformers of the dimerization product of 4oxocyclopent-2-en-1-yl acetate. The calculated energetics and chemical shifts indicate the experimental compound to be a combination of the head-to-head and head-to-tail conformers in the chair configuration, with the former one the main component. Based on the simulated NMR spectra, the spectral lines of the dimerization product of 4-oxocyclopent-2-en-1-yl acetate were identified. In a similar fashion, the intermolecular photodimerization reaction of 4CPA was successfully applied in copolymers, resulting in coupling of polymer chains to produce networks. Irradiation of solvent-cast poly(4CPA-co-LA) and poly(4CPA-co-MA) with UVA light resulted in cross-linked thin films, which possessed a high gel content. Further proof of the reactivity of the pendent cyclopentenone units was provided by IR spectroscopy, which was used to follow the disappearance of the internal double bond in the ring.

\section{ASSOCIATED CONTENT}

\section{SI Supporting Information}

The Supporting Information is available free of charge at https://pubs.acs.org/doi/10.1021/acs.macromol.9b02659.

${ }^{1} \mathrm{H}$ NMR and ${ }^{13} \mathrm{C}$ NMR of 4-hydroxycyclopentenone, 4oxocyclopent-2-en-1-yl acrylate (4CPA), and 4-oxocyclopent-2-en-1-yl acetate (1); MALDI-ToF-MS spectrum of the model copolymerization of 4CPA with 4-oxocyclopent-2-en-1-yl acetate; DEPT-135, DEPT-90 spectra, and DSC thermogram of the 4CPA homopolymer; DSC thermograms of the synthesized 4CPA copolymers; MS, DEPT, and HSQC analyses of the dimers of (1); swelling ratio graph of the cross-linked films from polymers $\operatorname{poly}\left(4 \mathrm{CPA}_{0.29}-c o-\mathrm{LA}_{0.71}\right)$ and $\operatorname{poly}\left(4 \mathrm{CPA}_{0.31}-c o-\mathrm{MA}_{0.69}\right)$ (PDF)

${ }^{13} \mathrm{C}-\mathrm{NMR},{ }^{1} \mathrm{H}-\mathrm{NMR},{ }^{17} \mathrm{O}-\mathrm{NMR}$, relative change (XLSX) Structural and vibrational stability of conformers of dimers of (1); derivation of out-projection of rotational and translational vibrational modes; impact of the bond length on the density functional theory calculation of chemical shifts; calculated ${ }^{1} \mathrm{H}$ NMR and ${ }^{13} \mathrm{C}$ NMR spectra, and oxygen chemical shifts of conformers of dimers of (1); optimized monomer and dimer molecular structures of compound (1) (ZIP)

\section{AUTHOR INFORMATION}

\section{Corresponding Author}

Katrien V. Bernaerts - Aachen-Maastricht Institute for Biobased Materials (AMIBM), Faculty of Science and Engineering
Maastricht University, 6167 RD Geleen, The Netherlands;

(1) orcid.org/0000-0002-2939-2963; Phone: +31 433882636;

Email: katrien.bernaerts@maastrichtuniversity.nl

\section{Authors}

Jules Stouten - Aachen-Maastricht Institute for Biobased Materials (AMIBM), Faculty of Science and Engineering, Maastricht University, 6167 RD Geleen, The Netherlands

Danny E. P. Vanpoucke - Aachen-Maastricht Institute for Biobased Materials (AMIBM), Faculty of Science and Engineering, Maastricht University, 6167 RD Geleen, The Netherlands; Institute for Materials Research (IMO), Hasselt University, 3590 Diepenbeek, Belgium

Guy Van Assche - Department of Physical Chemistry and Polymer Science, Faculty of Engineering Sciences, Vrije Universiteit Brussel (VUB), 1050 Brussels, Belgium

Complete contact information is available at: https://pubs.acs.org/10.1021/acs.macromol.9b02659

\section{Notes}

The authors declare no competing financial interest.

\section{ACKNOWLEDGMENTS}

J.S., D.E.P.V., and K.V.B. acknowledge the project D-NL-HIT carried out in the framework of INTERREG-Program Deutschland-Nederland, which is co-financed by the European Union; the MWIDE NRW; the Ministerie van Economische Zaken en Klimaat; and the provinces of Limburg, Gelderland, NoordBrabant, and Overijssel. The computational resources and services used in this work were provided by the VSC (Flemisch Supercomputer Center), funded by the Research Foundation Flanders (FWO) and the Flemisch Government-department EWI.

\section{REFERENCES}

(1) Climent, M. J.; Corma, A.; Iborra, S. Conversion of biomass platform molecules into fuel additives and liquid hydrocarbon fuels. Green Chem. 2014, 16, 516-547.

(2) Gallezot, P. Process options for converting renewable feedstocks to bioproducts. Green Chem. 2007, 9, 295-302.

(3) Mariscal, R.; Maireles-Torres, P.; Ojeda, M.; Sádaba, I.; Granados, M. L. Furfural: a renewable and versatile platform molecule for the synthesis of chemicals and fuels. Energy Environ. Sci. 2016, 9, 11441189.

(4) Decostanzi, M.; Auvergne, R.; Boutevin, B.; Caillol, S. Biobased phenol and furan derivative coupling for the synthesis of functional monomers. Green Chem. 2019, 21, 724-747. 
(5) Piancatelli, G.; Scettri, A.; Barbadoro, S. A useful preparation of 4substituted 5-hydroxy-3-oxocyclopentene. Tetrahedron Lett. 1976, 17, 3555-3558.

(6) Le Liepvre, M.; Ollivier, J.; Aitken, D. J. Synthesis of Functionalized Bicyclo [3.2. 0] heptanes-a Study of the [2+ 2] Photocycloaddition Reactions of 4-Hydroxycyclopent-2-enone Derivatives. Eur. J. Org. Chem. 2009, 2009, 5953-5962.

(7) Stensen, W.; Svendsen, J. S.; Hofer, O.; Sydnes, L. K. Photochemical $[2+2]$ Cycloadditions. 1ll. Addition of 4-Substituted 2-Cyclopentenones to Allene; Configuration Determination by Lanthanide-lnduced Shift Studies. Acta Chem. Scand. 1988, 42, 259268.

(8) Schrader, T. O.; Snapper, M. L. Stereodivergent synthesis of all 15F2 isoprostanes. J. Am. Chem. Soc. 2002, 124, 10998-11000.

(9) Shizuka, M.; Snapper, M. L. Selective synthesis of ent-15-epi-F2tisoprostane and a deuterated derivative. Synthesis 2007, 2007, 23972403.

(10) De Gregori, A.; Jommi, G.; Sisti, M.; Gariboldi, P.; Merati, F. Studies directed towards the total synthesis of dicyclopenta [a, d] cyclooctane terpenoids. Tetrahedron 1988, 44, 2549-2568.

(11) Farcet, J. B.; Himmelbauer, M.; Mulzer, J. Photochemical and thermal [2+2] cycloaddition to generate the bicyclo [3.2. 0] heptane core of bielschowskysin. Eur. J. Org. Chem. 2013, 2013, 4379-4398.

(12) Nettekoven, M.; Püllmann, B.; Martin, R. E.; Wechsler, D. Evaluation of a flow-photochemistry platform for the synthesis of compact modules. Tetrahedron Lett. 2012, 53, 1363-1366.

(13) Jacobo, S. H.; Chang, C.-T.; Lee, G.-J.; Lawson, J. A.; Powell, W. S.; Pratico, D.; FitzGerald, G. A.; Rokach, J. Total synthesis of 8, 12-isoiPF $3 \alpha$-VI, an EPA-derived isoprostane: stereoselective introduction of the fifth asymmetric center. J. Org. Chem. 2006, 71, 1370-1379.

(14) Jeroncic, L. O.; Cabal, M. P.; Danishefsky, S. J.; Shulte, G. M. On the diastereofacial selectivity of Lewis acid-catalyzed carbon-carbon bond forming reactions of conjugated cyclic enones bearing electronwithdrawing substituents at the. gamma.-position. J. Org. Chem. 1991, $56,387-395$.

(15) Dols, P. P. M.; Klunder, A. J.; Zwanenburg, B. 4Hydroxycyclopent-2-en-1-one and derivatives as chiral synthetic equivalents of cyclopentadienone in asymmetric Diels-Alder reactions. Tetrahedron 1994, 50, 8515-8538.

(16) Morita, Y.; Suzuki, M.; Noyori, R. An organozinc aid in alkylation and acylation of lithium enolates. J. Org. Chem. 1989, 54, 1785-1787.

(17) Suzuki, M.; Morita, Y.; Koyano, H.; Koga, M.; Noyori, R. Threecomponent coupling synthesis of prostaglandins. A simplified, general procedure. Tetrahedron 1990, 46, 4809-4822.

(18) Lipshutz, B. H.; Wood, M. R.; Tirado, R. Michael additions of functionalized organozinc reagents mediated by catalytic quantities of copper (I). J. Am. Chem. Soc. 1995, 117, 6126-6127.

(19) Fürstner, A.; Grela, K.; Mathes, C.; Lehmann, C. W. Novel and flexible entries into prostaglandins and analogues based on ring closing alkyne metathesis or alkyne cross metathesis. J. Am. Chem. Soc. 2000, 122, 11799-11805.

(20) Ichikawa, M.; Takahashi, M.; Aoyagi, S.; Kibayashi, C. Total synthesis of $(-)$-incarvilline, $(+)$-incarvine $\mathrm{C}$, and (-)-incarvillateine. J. Am. Chem. Soc. 2004, 126, 16553-16558.

(21) O’Byrne, A.; Murray, C.; Keegan, D.; Palacio, C.; Evans, P.; Morgan, B. S. The thio-adduct facilitated, enzymatic kinetic resolution of 4-hydroxycyclopentenone and 4-hydroxycyclohexenone. Org. Biomol. Chem. 2010, 8, 539-545.

(22) Basra, S. K.; Drew, M. G.; Mann, J.; Kane, P. D. A novel approach to bis-isoxazolines using a latent form of cyclopentadienone. J. Chem. Soc., Perkin Trans. 1 2000, 3592-3598.

(23) Adembri, G.; Paoli, M. L.; Rossi, P.; Sega, A. Synthesis of enantiopure bis-isoxazolines from (4R)-(+)-4-acetoxycyclopent-2enone. Tetrahedron: Asymmetry 2001, 12, 619-623.

(24) Mitscher, L.; Clark, G., III; Hudson, P. Terrein, an optically active prostaglandin synthon of fungal origin. II. Chemical conversion to 4 (R)-acetoxy-2-cyclopentenone. Tetrahedron Lett. 1978, 19, 25532556.
(25) Schiess, P.; Suter, C. Photochemische Bildung zweier [2+ 2]Dimeren von Cyclopentadienon aus 5-Acetoxy-3-oxocyclopenten. Synthesis 1978, 1978, 543.

(26) Davidson, R. Radiation Curing; iSmithers Rapra Publishing, 2001; Vol. 12.

(27) Huyck, R. H.; Trenor, S. R.; Love, B. J.; Long, T. E. Photodimerization of coumarin functionalized poly (alkyl acrylate) and poly (alkyl methacrylate) random copolymers: Influence of copolymer composition on photocrosslinking. J. Macromol. Sci., Part A: Pure Appl. Chem. 2007, 45, 9-15.

(28) Imai, Y.; Naka, K.; Chujo, Y. Reversible formation of interpenetrating polymer network structure in organic-inorganic polymer hybrids. Polym. J. 1998, 30, 990.

(29) Trenor, S. R.; Long, T. E.; Love, B. J. Development of a lightdeactivatable PSA via photodimerization. J. Adhes. 2005, 81, 213-229.

(30) Delzenne, G.; Laridon, U. Photosensitive Polymers-Synthesis and Properties of Coumarin-Modified Polymers; Industrie Chimique BelgeBelgische Chemische Industrie, 1966; p 158.

(31) Minsk, L.; Smith, J.; Van Deusen, W.; Wright, J. Photosensitive polymers. I. Cinnamate esters of poly (vinyl alcohol) and cellulose. J. Appl. Polym. Sci. 1959, 2, 302-307.

(32) Robertson, E.; Van Deusen, W.; Minsk, L. Photosensitive polymers. II. Sensitization of poly (vinyl cinnamate). J. Appl. Polym. Sci. 1959, 2, 308-311.

(33) Lasseuguette, E.; Gandini, A.; Belgacem, M. N.; Timpe, H.-J. Synthesis, characterization and photocrosslinking of copolymers of furan and aliphatic hydroxyethylesters prepared by transesterification. Polymer 2005, 46, 5476-5483.

(34) Xu, J.-F.; Chen, Y.-Z.; Wu, L.-Z.; Tung, C.-H.; Yang, Q.-Z. Dynamic covalent bond based on reversible photo [4+4] cycloaddition of anthracene for construction of double-dynamic polymers. Org. Lett. 2013, 15, 6148-6151.

(35) Radl, S. V.; Roth, M.; Gassner, M.; Wolfberger, A.; Lang, A.; Hirschmann, B.; Trimmel, G.; Kern, W.; Griesser, T. Photo-induced crosslinking and thermal de-crosslinking in polynorbornenes bearing pendant anthracene groups. Eur. Polym. J. 2014, 52, 98-104.

(36) Zheng, Y.; Micic, M.; Mello, S. V.; Mabrouki, M.; Andreopoulos, F. M.; Konka, V.; Pham, S. M.; Leblanc, R. M. PEG-based hydrogel synthesis via the photodimerization of anthracene groups. Macromolecules 2002, 35, 5228-5234.

(37) Coursan, M.; Desvergne, J. P.; Deffieux, A. Reversible photodimerisation of $\omega$-anthrylpolystyrenes. Macromol. Chem. Phys. 1996, 197, 1599-1608.

(38) Akiyama, M.; Yoshida, K.; Mori, H. Controlled synthesis of vinylfunctionalized homopolymers and block copolymers by RAFT polymerization of vinyl methacrylate. Polymer 2014, 55, 813-823.

(39) Ma, J.; Cheng, C.; Sun, G.; Wooley, K. L. Well-defined polymers bearing pendent alkene functionalities via selective RAFT polymerization. Macromolecules 2008, 41, 9080-9089.

(40) Lin, Y.; Liu, X.; Li, X.; Zhan, J.; Li, Y. Reversible additionfragmentation chain transfer mediated radical polymerization of asymmetrical divinyl monomers targeting hyperbranched vinyl polymers. J. Polym. Sci., Part A: Polym. Chem. 2007, 45, 26-40.

(41) Chiefari, J.; Chong, Y.; Ercole, F.; Krstina, J.; Jeffery, J.; Le, T. P.; Mayadunne, R. T.; Meijs, G. F.; Moad, C. L.; Moad, G.; et al. Living free-radical polymerization by reversible addition-fragmentation chain transfer: the RAFT process. Macromolecules 1998, 31, 5559-5562.

(42) Beerthuis, R.; Rothenberg, G.; Shiju, N. R. Catalytic routes towards acrylic acid, adipic acid and $\varepsilon$-caprolactam starting from biorenewables. Green Chem. 2015, 17, 1341-1361.

(43) Wittcoff, H. A.; Reuben, B. G.; Plotkin, J. S. Industrial Organic Chemicals; John Wiley \& Sons, 2012.

(44) Gupta, J.; Keddie, D. J.; Wan, C.; Haddleton, D. M.; McNally, T. Functionalisation of MWCNTs with poly (lauryl acrylate) polymerised by $\mathrm{Cu}(0)$-mediated and RAFT methods. Polym. Chem. 2016, 7, 38843896.

(45) Engler, M. S.; Crotty, S.; Barthel, M. J.; Pietsch, C.; Knop, K.; Schubert, U. S.; Böcker, S. COCONUT-An Efficient Tool for 
Estimating Copolymer Compositions from Mass Spectra. Anal. Chem. 2015, 87, 5223-5231.

(46) Ulbrich, K.; Kreitmeier, P.; Reiser, O. Microwave-or microreactor-assisted conversion of furfuryl alcohols into 4-hydroxy-2cyclopentenones. Synlett 2010, 2010, 2037-2040.

(47) Ghorpade, S. R.; Bastawade, K. B.; Gokhale, D. V.; Shinde, P. D.; Mahajan, V. A.; Kalkote, U. R.; Ravindranathan, T. Enzymatic kinetic resolution studies of racemic 4-hydroxycyclopent-2-en-1-one using Lipozyme IM. Tetrahedron: Asymmetry 1999, 10, 4115-4122.

(48) Kresse, G.; Joubert, D. From ultrasoft pseudopotentials to the projector augmented-wave method. Phys. Rev. B 1999, 59, 1758-1775.

(49) Blöchl, P. E. Projector augmented-wave method. Phys. Rev. B 1994, 50, 17953-17979.

(50) Perdew, J. P.; Burke, K.; Ernzerhof, M. Generalized Gradient Approximation Made Simple. Phys. Rev. Lett. 1996, 77, 3865-3868.

(51) Grimme, S.; Ehrlich, S.; Goerigk, L. Effect of the damping function in dispersion corrected density functional theory. J. Comput. Chem. 2011, 32, 1456-1465.

(52) Vanpoucke, D. E. P. Fingerprinting defects in diamond: Partitioning the vibrational spectrum. 2020, arXiv preprint arXiv:2001.06277. https://arxiv.org/abs/2001.06277.

(53) HIVE-tools v4.x, 2005. https://github.com/DannyVanpoucke/ HIVE4-tools.

(54) Vanpoucke, D. E.; Bultinck, P.; Van Driessche, I. Extending Hirshfeld-I to bulk and periodic materials. J. Comput. Chem. 2013, 34, 405-417.

(55) Vanpoucke, D. E.; Van Driessche, I.; Bultinck, P. Reply to 'comment on "extending Hirshfeld-I to bulk and periodic materials". J. Comput. Chem. 2013, 34, 422-427.

(56) Becke, A. D. A multicenter numerical integration scheme for polyatomic molecules. J. Chem. Phys. 1988, 88, 2547-2553.

(57) Lebedev, V. I.; Laikov, D. A Quadrature Formula for the Sphere of the 131st Algebraic Order of Accuracy; Pleiades Publishing, Ltd.: Doklady Mathematics, 1999; pp 477-481.

(58) Pickard, C. J.; Mauri, F. All-electron magnetic response with pseudopotentials: NMR chemical shifts. Phys. Rev. $B$ 2001, 63, No. 245101.

(59) Yates, J. R.; Pickard, C. J.; Mauri, F. Calculation of NMR chemical shifts for extended systems using ultrasoft pseudopotentials. Phys. Rev. B 2007, 76, No. 024401.

(60) de Wijs, G.; Laskowski, R.; Blaha, P.; Havenith, R.; Kresse, G.; Marsman, M. NMR shieldings from density functional perturbation theory: GIPAW versus all-electron calculations. J. Chem. Phys. 2017, 146, No. 064115.

(61) Heuts, J. P. A. Theory of Radical Reactions. In Handbook of Radical Polymerization; Matyjaszewski, K.; Davis, T. P., Eds.; John Wiley \& Sons, Inc.: New York, 2002; pp 1-76.

(62) Ballard, N.; Asua, J. M. Radical polymerization of acrylic monomers: An overview. Prog. Polym. Sci. 2018, 79, 40-60.

(63) Ballard, N.; Rusconi, S.; Akhmatskaya, E.; Sokolovski, D.; de la Cal, J. C.; Asua, J. M. Impact of competitive processes on controlled radical polymerization. Macromolecules 2014, 47, 6580-6590.

(64) Ballard, N.; Hamzehlou, S.; Asua, J. M. Intermolecular transfer to polymer in the radical polymerization of n-butyl acrylate. Macromolecules 2016, 49, 5418-5426.

(65) Keddie, D. J.; Moad, G.; Rizzardo, E.; Thang, S. H. RAFT agent design and synthesis. Macromolecules 2012, 45, 5321-5342.

(66) Jordan, E. F., Jr; Feldeisen, D. W.; Wrigley, A. Side-chain crystallinity. I. Heats of fusion and melting transitions on selected homopolymers having long side chains. J. Polym. Sci., Part A-1: Polym. Chem. 1971, 9, 1835-1851.

(67) Jordan, E. F., Jr; Artymyshyn, B.; Speca, A.; Wrigley, A. Sidechain crystallinity. II. Heats of fusion and melting transitions on selected copolymers incorporating n-octadecyl acrylate or vinyl stearate. J. Polym. Sci., Part A-1: Polym. Chem. 1971, 9, 3349-3365.

(68) Dong, W.; Li, H.; Chen, M.; Ni, Z.; Zhao, J.; Yang, H.; Gijsman, P. Biodegradable bio-based polyesters with controllable photocrosslinkability, thermal and hydrolytic stability. J. Polym. Res. 2011, $18,1239-1247$.
(69) Eaton, P. E. On the Mechanism of the Photodimerization of Cyclopentenone. J. Am. Chem. Soc. 1962, 84, 2454-2455.

(70) Ruhlen, J. L.; Leermakers, P. A. On the Photodimerization of Cyclopentenone. J. Am. Chem. Soc. 1966, 88, 5671-5672.

(71) Ruhlen, J. L.; Leermakers, P. A. Photochemistry of cyclopentenone in various media. J. Am. Chem. Soc. 1967, 89, 4944-4948.

(72) Wagner, P. J.; Bucheck, D. J. Inefficiency and reversibility in the photodimerization of 2-cyclopentenone. Can. J. Chem. 1969, 47, 713714.

(73) Experimental chemical shifts are generally presented relative to a specific reference. We have chosen to present the calculated chemical shifts in their absolute calculated form, allowing for direct comparison to calculations using different methods. One might consider performing a shift on the calculated spectrum using a calculated reference or the experimental data directly. However, as we discuss in the SI, no unique shift value exists in the case of sub-ppm resolution spectra. 